\title{
Common Blood Flow Changes Across Visual Tasks: I. Increases in Subcortical Structures and Cerebellum but Not in Nonvisual Cortex
}

\section{Citation}

Shulman, Gordon L., Maurizio Corbetta, Randy Lee Buckner, Julie A. Fiez, Francis M. Miezin, Marcus E. Raichle, and Steven E. Petersen. 1997. Common blood flow changes across visual tasks: I. Increases in subcortical structures and cerebellum but not in nonvisual cortex. Journal of Cognitive Neuroscience 9(5): 624-647.

\section{Published Version}

doi:10.1162/jocn.1997.9.5.624

\section{Permanent link}

http://nrs.harvard.edu/urn-3:HUL.InstRepos:3627134

\section{Terms of Use}

This article was downloaded from Harvard University's DASH repository, and is made available under the terms and conditions applicable to Other Posted Material, as set forth at http:// nrs.harvard.edu/urn-3:HUL.InstRepos:dash.current.terms-of-use\#LAA

\section{Share Your Story}

The Harvard community has made this article openly available.

Please share how this access benefits you. Submit a story.

Accessibility 


\title{
Common Blood Flow Changes across Visual Tasks: I. Increases in Subcortical Structures and Cerebellum but Not in Nonvisual Cortex
}

\author{
Gordon L. Shulman, Maurizio Corbetta, Randy L. Buckner, \\ Julie A. Fiez, Francis M. Miezin, Marcus E. Raichle, and \\ Steven E. Petersen \\ Washington University School of Medicine
}

\begin{abstract}
Nine positron emission tomography (PET) studies of human visual information processing were reanalyzed to determine the consistency across experiments of blood flow increases during active tasks relative to passive viewing of the same stimulus array. No consistent blood flow increases were found in cerebral cortex outside of the visual system, but increases were seen in the thalamus and cerebellum. Although most tasks involve increases in arousal, establishing an intention or behavioral goal, setting up control structures for sequencing task operations, detecting targets, etc., these operations do not produce blood flow increases, detectable with the present methods, in localized cortical regions that are common across tasks. Common subcortical regions, however, may be involved.

A left cerebellar and a medial cerebellar focus reflected motor-related processes. Blood flow increases in these regions only occurred in experiments in which the subject made an overt response and were largest when the response was made in the active but not passive condition. These motor-related processes were more complex than simple motor execution, however, since increases were still present when the response was made in both the active and passive conditions. These cerebellar increases may reflect processes related to response
\end{abstract}

selection. Blood flow increases in a right cerebellar region were not motor-related. Increases were not modulated by the presence or absence of motor responses during either the active or passive conditions, and increases were sensitive to withinexperiment variables that held the motor response constant. Increases occurred in both language and nonlanguage tasks and appeared to involve a general nonmotor process, but the nature of that process was difficult to specify.

A right thalamic focus was sensitive to variables related to focal attention, suggesting that this region was involved in attentional engagement. Right thalamic increases were also correlated over conditions with increases in the left and medial cerebellum, perhaps reflecting additional contributions from motor-related nuclei receiving cerebellar projections.

Blood flow increases in a left thalamic focus were completely uncorrelated over conditions with increases in the right thalamus, indicating that it was involved in different functions. Both the left thalamus and right cerebellum yielded larger blood flow increases when subjects performed a complex rather than simple language task, possibly reflecting a language-related pathway. Blood flow increases in the left thalamus were also observed, however, during nonlanguage tasks.

\section{INTRODUCTION}

Although many studies have found that specific regions of the brain are activated during particular tasks, it is also possible that some brain regions perform very general functions and are active across a wide variety of tasks. The arousal and effort associated with most cognitive tasks (Kahneman, 1973), for example, may involve specific brain regions. Pardo, Fox, \& Raichle (1991) have reported a variety of right-hemisphere increases that occur in vigilance tasks, which require sustained attention. Conversely, right-hemisphere lesions decrease the ability of patients to maintain alertness, as manifested by an overall slowing in reaction time (Ladavas, 1987) that is particularly marked in the absence of a warning signal (Posner, Inhoff, Friedrich, \& Cohen, 1987).

Task preparation may also involve specific brain regions. A warning signal preceding the onset of an imperative stimulus triggers a preparatory state of alertness (Posner, 1978) and/or motor readiness (Gaillard, 1977). Appropriate response selection rules may be activated (De Jong, 1995) as well as the instructions for the sequence of operations that comprise the relevant task (i.e., a task memory/controller). Components of a preparatory state are thought to be indexed by a scalp potential, the contingent negative variation (CNV) (Walter, Cooper, Aldridge, McCallum, \& Winter, 1964). Both cortical (Rosahl \& Knight, 1995) and subcortical structures (Gazzaniga \& Hillyard, 1973) have been implicated in the generation of the CNV.

Many tasks show attentional limitations (i.e., performing the task generates interference with other tasks). 
Interference between tasks may reflect "local" causes such as the use of similar input (i.e., vision) or output (i.e., manual responses) systems (McLeod, 1978; Treisman \& Davies, 1973) but may also reflect a general component common to all tasks (Posner, 1978) that involves a particular brain region. Posner and Petersen (1990) have suggested that the anterior cingulate is part of an anterior attention system that is involved in target detection and controls posterior areas involved in spatial orienting (Posner et al., 1987).

We have analyzed PET data from a large number of studies of human visual information processing (Tables 1 and 2) in order to determine if there are any brain regions that showed blood flow increases which generalized across tasks. Each study involved a set of active conditions, in which subjects performed a variety of tasks upon a stimulus, and a passive condition, in which the same stimulus was presented, but the subject was not given a task. A comparison of active and passive conditions therefore isolated neural processes that were task contingent, while holding constant automatic processes triggered by the presence of a stimulus. Any brain region that generalized over tasks should be revealed in an image that averages active minus passive blood flow changes across the tasks in all studies.

\section{RESULTS}

The first set of analyses determined if an "overall megaimage," which averaged the active minus passive scan pairs from all nine experiments, contained any reliable or large magnitude blood flow increases (Replication
Analyses, Analyses of Additional Blood Flow Changes). Although this megaimage should include any increases that generalized over tasks, it may also contain increases that were confined to a subset of experiments but were sufficient in size to produce statistically significant effects. In four of nine experiments, for example, subjects made motor responses in the active but not passive conditions, producing large motor-related increases. A second set of analyses (Between-Experiment Analyses) therefore examined the consistency over experiments of the increases identified from the first set of analyses.

\section{Replication Analyses}

Blood flow increases were identified in a megaimage based on a hypothesis-generating (generate) group of scan pairs and tested for reliability via a one-sample $t$ test in a nonoverlapping hypothesis-testing (test) group of scan pairs. Both the generate and test groups included scan pairs from all nine experiments.

\section{Cortical Foci}

Sixteen cortical foci were observed in the generate megaimage that passed the selection criteria: (1) the magnitude exceeded 10 PET counts, (2) the foci were adequately sampled ( $\mathrm{N}>50$ ), and (3) foci were not located in occipital cortex (see (Shulman, Corbetta, et al., 1997) for an analysis of increases in early visual cortex) ${ }^{1}$ (Table 3). Eight foci replicated at a 0.05 significance level, with six of these passing a 0.05 level, Bonferronicorrected for the number of comparisons $(p<0.003)$.

Table 1. Sample sizes for all experiments. For those experiments in which subjects contributed scan pairs to both the generate and test groups, the sum of the generate and test group subjects (total) exceeded the total number of subjects in the experiment. The last column indicates whether a manual (m), vocal (v), or no response (-) was made in the active and passive conditions.

\begin{tabular}{|c|c|c|c|c|c|c|c|c|}
\hline \multirow[b]{2}{*}{ Study } & \multicolumn{2}{|c|}{ Generate } & \multicolumn{2}{|c|}{ Test } & \multicolumn{2}{|c|}{ Total } & \multicolumn{2}{|c|}{ Response } \\
\hline & Subjects & $\begin{array}{l}\text { Scan } \\
\text { Pairs }\end{array}$ & Subjects & $\begin{array}{l}\text { Scan } \\
\text { Pairs }\end{array}$ & Subjects & $\begin{array}{l}\text { Scan } \\
\text { Pairs }\end{array}$ & Active & Passive \\
\hline 1. Same-Different Discrimination & 10 & 22 & 10 & 21 & 10 & 43 & m & m \\
\hline 2. Visual Search 1 & 10 & 17 & 12 & 24 & 13 & 41 & - & - \\
\hline 3. Visual Search 2 & 14 & 27 & 14 & 40 & 14 & 67 & $\mathbf{m}$ & m \\
\hline 4. Visual Search 3 & 15 & 35 & 15 & 37 & 15 & 72 & $\mathrm{~m}$ & m \\
\hline 5. Spatial Attention & 14 & 17 & 14 & 20 & 18 & 37 & m & - \\
\hline 6. Language & 6 & 6 & 7 & 17 & 13 & 23 & $\mathbf{v}$ & - \\
\hline 7. Practice Language & 12 & 32 & 13 & 39 & 13 & 71 & $\mathbf{v}$ & - \\
\hline 8. Memory & 10 & 16 & 13 & 32 & 23 & 48 & $\mathbf{v}$ & - \\
\hline 9. Cross-modal Imagery & 6 & 10 & 7 & 14 & 13 & 24 & $\mathrm{~m}$ & $\mathbf{m}$ \\
\hline Total & 97 & 182 & 105 & 244 & 132 & 426 & & \\
\hline
\end{tabular}


Table 2. Display Characteristics and Task Descriptions for Individual Experiments.

\begin{tabular}{cl}
\hline \multicolumn{1}{c}{ Experiment } & \multicolumn{1}{c}{ Display } \\
\hline $\begin{array}{l}\text { Successive Same- } \\
\text { Different Discrimi- } \\
\text { nation (Corbetta, } \\
\begin{array}{l}\text { Miezin, Shulman, et } \\
\text { al., 1991) }\end{array}\end{array}$ & $\begin{array}{l}\text { Two 400-msec arrays of } \\
\text { moving, colored rectangles, } \\
\text { separated by } 200 \text { msec. }\end{array}$ \\
$\begin{array}{l}\text { Visual Search 1 } \\
\text { (Corbetta et al., } \\
1990,1991)\end{array}$ & $\begin{array}{l}\text { Four colored squares, each } \\
\text { at } 17^{\circ}, 100-\text { msec duration }\end{array}$ \\
& $\begin{array}{l}\text { Four colored rectangles, } \\
\text { each at } 17^{\circ}, 100-\text { msec } \\
\text { duration }\end{array}$ \\
&
\end{tabular}

Visual Search 2 (Corbetta et al., 1990, 1991)

Visual Search 3 (Corbetta et al., 1995)

Spatial Attention (Corbetta et al., 1993)

Language (Petersen et al., 1989)

Practice Language (Raichle et al., 1994)

Memory (Buckner et al., 1995)

Cross-Modal Imagery (Fiez et al., 1995)
Same as Visual Search 1 but eccentricity $=5^{\circ}$.

Four winows of moving, colored dots. Each window at $4^{\circ}, 500$-msec duration.

Bilateral horizontal array of 10 boxes. Asterisk appears for $150 \mathrm{msec}$ in each box, in a predictable sequence.

Noun printed in uppercase letters, $1^{\circ}$ below fixation, 150-msec duration.

Noun printed in uppercase letters, $1^{\circ}$ below fixation, 150-msec duration.

Three-letter word stem presented in uppercase letters $1^{\circ}$ below fixation, 3-sec duration.

Word presented in uppercase letters $1^{\circ}$ below fixation, 150-msec duration.
Task

1. Color: Do colors in two arrays match?

2. Motion: Do speeds in two arrays match?

3. Shape: Do rectangles in two arrrays match?

4. Divided: Do colors, speeds, and rectangles in two arrays match? (Note: 2-choice manual unspeeded response in active tasks; alternating keypress on successive trials in passive condition.)

$1 \& 2$. Color: Does array contain particular color? Target color present on $5 \%$ or $50 \%$ of trials.

3 \& 4. Color-form: Does array contain oriented rectangle of particular color? Target rectangle present on $5 \%$ or $50 \%$ of trials. (Note: No overt response during either active or passive condition. In active tasks, subjects report an approximate target percentage after scan.)

$1 \&$ 2. Color: Same as Visual Search 1. Target frequency 5 and $45 \%$. 3 \& 4. Color-form: Same as Visual Search 1. Target frequency 5 and $45 \%$. (Note: 2-choice manual unspeeded response in active tasks; alternating keypress on successive trials in passive condition.)

$1 \& 2$. Color: Is particular color present? Target frequency 20 and $80 \%$. $3 \& 4$. Motion: 1s particular speed present? Target frequency 20 and $80 \%$. $5 \& 6$. Conjunction: Is conjunction of color and speed present? Target frequency 20 and $80 \%$.

(Note: 2 -choice manual speeded response in active tasks; alternating keypress on successive trials in passive condition.)

1. Left field/left direction: Detect asterisk moving in left field and direction?

2. Left field/right direction: Detect asterisk moving in left field, right direction?

3. Right field/left direction: Detect asterisk moving in right field, left direction?

4. Right field/right direction: Detect asterisk moving in right field and direction?

(Note: Simple speeded manual response in active tasks; no response in passive condition.)

1. Read: Subject reads the noun.

2. Verb-generation: Subject names a verb appropriate to the noun.

(Note: speeded vocal response in active tasks; no response in passive condition.)

1. Read naive: Subject sees list of nouns for first time.

2. Verb-generation naive: Subject sees list of nouns for first time.

3.Verb-generation practice: Noun list has been practiced 10 times.

4. Read practice: Noun list has been practiced 10 times.

5. Verb-generation novel: Task conducted with new list.

6. Read novel: Task conducted with new list.

(Note: Speeded vocal response in active tasks; no response in passive condition.)

Subjects see study list of words prior to each condition and indicates how much they liked each word.

1. Baseline: Subjects complete word stems.

2. Priming: Subjects complete word stems; $50 \%$ of words from study list

3. Cued-recall: Subjects recall words from study list; $50 \%$ of words from study list.

(Note: Speeded vocal response in active tasks; no response in passive condition.)

1. Orthographic: Does word contain lowercase ascender (i.e., d)?

2. Phonological: Does word contain long vowel?

(Note: 2 -choice manual speeded response in active tasks; alternating keypress on successive trials in passive condition.) 
Table 3. Active minus passive increases from the overall megaimage. The first column shows the number of each focus displayed in Figure 1. Succeeding columns on the left show the coordinates of each replicated focus from the generate group and the magnitude and 1-tailed $p$ value for the replication of that focus in the test group (ns refers to $p>0.05$ ). Columns on the right show the nearest focus in the generate plus test group for each replicated generate focus as well as all generate plus test foci with a magnitude exceeding 10 PET counts. Some replicated foci from the generate group did not show distinct foci in the generate plus test group and therefore do not have corresponding entries in the right panel of the table (e.g., right BA 6). Conversely, two foci in the generate plus test megaimage from BA 6 did not produce distinct foci in the generate megaimage and therefore do not have corresponding entries in the left panel.

\begin{tabular}{|c|c|c|c|c|c|c|c|c|c|c|c|c|}
\hline \multirow[b]{2}{*}{ Area } & \multirow[b]{2}{*}{ Focus \# } & \multicolumn{3}{|c|}{$\begin{array}{l}\text { Generate } \\
\text { coordinate }\end{array}$} & \multicolumn{2}{|r|}{ Test } & \multicolumn{6}{|c|}{ Generate plus Test } \\
\hline & & $X$ & $Y$ & $Z$ & Mag. & $p$ value & $x$ & $Y$ & $Z$ & $N$ & Mag. & $\mathrm{z}$-score \\
\hline \multicolumn{13}{|l|}{ Frontal Lobe } \\
\hline $\begin{array}{l}\text { L } 6 \text { (superior } \\
\text { precentral gyrus) }\end{array}$ & 1 & & & & & & -43 & -7 & 54 & 101 & 13 & 4.83 \\
\hline Medial 6 (SMA) & 2 & -1 & 1 & 56 & 25 & $<0.0001$ & & & & & & \\
\hline L 4 (central sulcus) & 3 & -45 & -13 & 38 & 14 & $<0.0001$ & -45 & -15 & 40 & 132 & 19 & 6.03 \\
\hline L 6/4 (precentral gyrus) & 4 & -59 & -1 & 30 & 16 & $<0.0001$ & -51 & -3 & 30 & 132 & 19 & 5.64 \\
\hline L 6 (precentral gyrus) & 5 & & & & & & -29 & -3 & 28 & 132 & 11 & 4.37 \\
\hline R 6/4 (precentral gyrus) & 6 & 61 & -5 & 26 & 19 & $<0.0001$ & 59 & -5 & 28 & 132 & 20 & 6.70 \\
\hline L 44 & 7 & -57 & 13 & 18 & 10 & $<0.001$ & -61 & 11 & 20 & 132 & 13 & 4.60 \\
\hline R $45 / 44$ & 8 & 33 & 19 & 14 & 3 & ns & 31 & 23 & 10 & 131 & 11 & 3.64 \\
\hline R 4 (central sulcus) & & 35 & -21 & 54 & 9 & $<0.005$ & & & & & & \\
\hline R 6 (precentral gyrus) & & 47 & -5 & 40 & 14 & $<0.0005$ & & & & & & \\
\hline \multicolumn{13}{|l|}{ Parietal Lobe } \\
\hline L 3 & & -51 & -15 & 56 & 7 & $<0.005$ & & & & & & \\
\hline \multicolumn{13}{|l|}{ Subcortical } \\
\hline L thalamus/caudate & 9 & -19 & -23 & 20 & 12 & $<0.0001$ & -17 & -25 & 16 & 132 & 14 & 5.78 \\
\hline L thalamus & 10 & -7 & -17 & 8 & 14 & $<0.0001$ & -5 & -17 & 8 & 132 & 16 & 5.39 \\
\hline \multirow[t]{2}{*}{$R$ thalamus } & 11 & 11 & -15 & 8 & 16 & $<0.0001$ & 11 & -21 & 12 & 132 & 18 & 6.77 \\
\hline & & 15 & -31 & 12 & 14 & $<0.0001$ & & & & & & \\
\hline L cerebellum & 12 & -23 & -59 & -12 & 31 & $<0.0001$ & -23 & -61 & -14 & 113 & 31 & 8.12 \\
\hline Medial cerebellum & 13 & -5 & -75 & -10 & 28 & $<0.0001$ & -3 & -69 & -8 & 129 & 39 & 8.21 \\
\hline $\mathrm{R}$ cerebellum & 14 & 25 & -59 & -18 & 22 & $<0.0001$ & 33 & -63 & -18 & 97 & 25 & 6.73 \\
\hline
\end{tabular}

Four of the six foci had a corresponding focus in the generate plus test megaimage that combined the generate and test groups (right-hand panel of Table 3). These four foci (see Figure 1) occurred in the left central sulcus (Brodmann area, BA 4), the left and right precentral gyrus (BA 6/4), and left frontal cortex (BA 44). The left frontal (BA 44) focus plotted on the boundary of the brain and may have been artifactual. ${ }^{2}$

\section{Subcortical Foci}

The generate megaimage contained eight subcortical foci that met the selection criteria. Seven foci replicated in the test group at a Bonferroni-corrected 0.05 level, and six of these had a corresponding focus in the generate plus test megaimage. These six foci were localized in the right and left thalamus, the border between the 


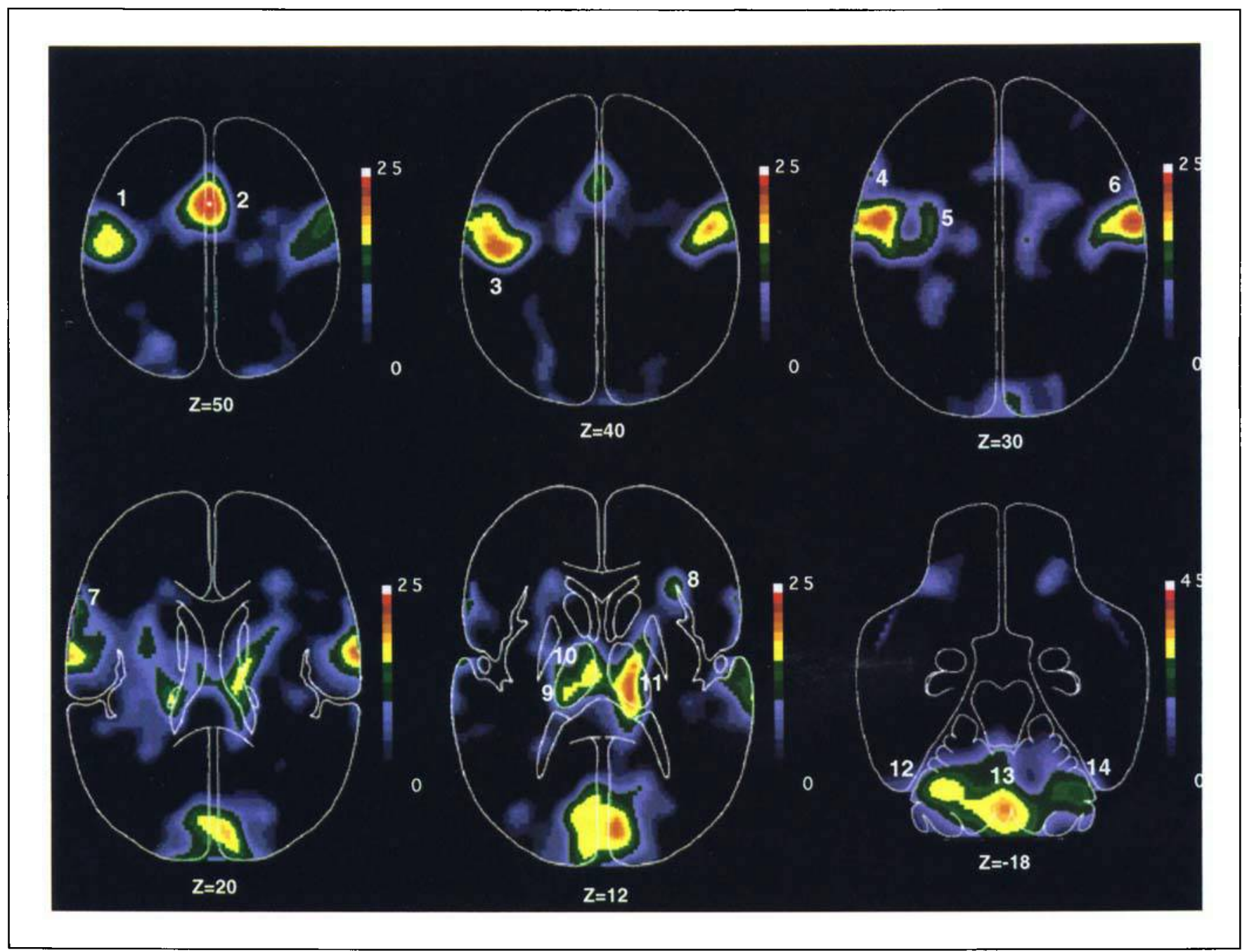

Figure 1. Active minus passive blood flow increases from the overall megaimage. Each numbered focus exceeded a magnitude threshold of ten PET counts in the overall megaimage. SMA (focus no. 2) did not produce a separate focus within this megaimage but merged with a more superior focus. It is included for completeness. The magnitude scale for $z=-18$ is different from the scale for the other slices since the cerebellar increases were larger in magnitude. Increases within cerebral cortex (nos. 1 through 8 ) are evident at several frontal areas, but as discussed in the text, these increases were generally confined to experiments in which a response was made in the active but not passive condition. Subcortical (nos. 9 through 11) and cerebellar (nos. 12 through 14) foci, however, were consistent across experiments. Foci nos. 9 and 10 appear merged in the image but are separate at slices corresponding to their peak magnitudes.

superior left thalamus and overlying regions of the caudate nucleus, the medial cerebellum, and the left and right cerebellum.

\section{Analyses of Additional Blood Flow Increases}

Since the replication analysis may have been conservative, the generate plus test megaimage was inspected for all well-sampled foci $(N>50)$ exceeding 10 PET counts. Seven foci, all in cortex, met these criteria. Although five of these foci were previously observed in the generate megaimage [one of these five (right BA 45/44) had not replicated in the test group], two foci in left premotor cortex (BA 6) were new. Since these foci were not tested for replication, their reliability is uncertain, but they are included in subsequent analyses for completeness. Of all cortical foci less than 10 counts, only one had a $z$ score $>3.08$. It plotted near right premotor cortex (BA 6), roughly homologous to focus no. 5 in left premotor cortex.

\section{Between-Experiments Analyses}

The above analyses established that the overall megaimage contained four replicable cortical foci, three additional cortical foci from the magnitude screen, and six 
Figure 2. Each graph shows the active minus passive magnitude (in PET counts) across experiments at a single focus defined by the overall megaimage. The $p$ value for a 1-factor ANOVA with Experiments as the factor is shown for each focus. The four experiments involving language-related processes are shown on the right of each graph, while the five nonlanguage experiments are on the left. Experiments in bold type involved a motor response in the active conditions but no response in the passive conditions. Three of these experiments were language-related (Language, Practice Language, and Memory) and involved a vocal response in the active task, while the fourth (Spatial Attention) was nonlanguage related and involved a manual response.

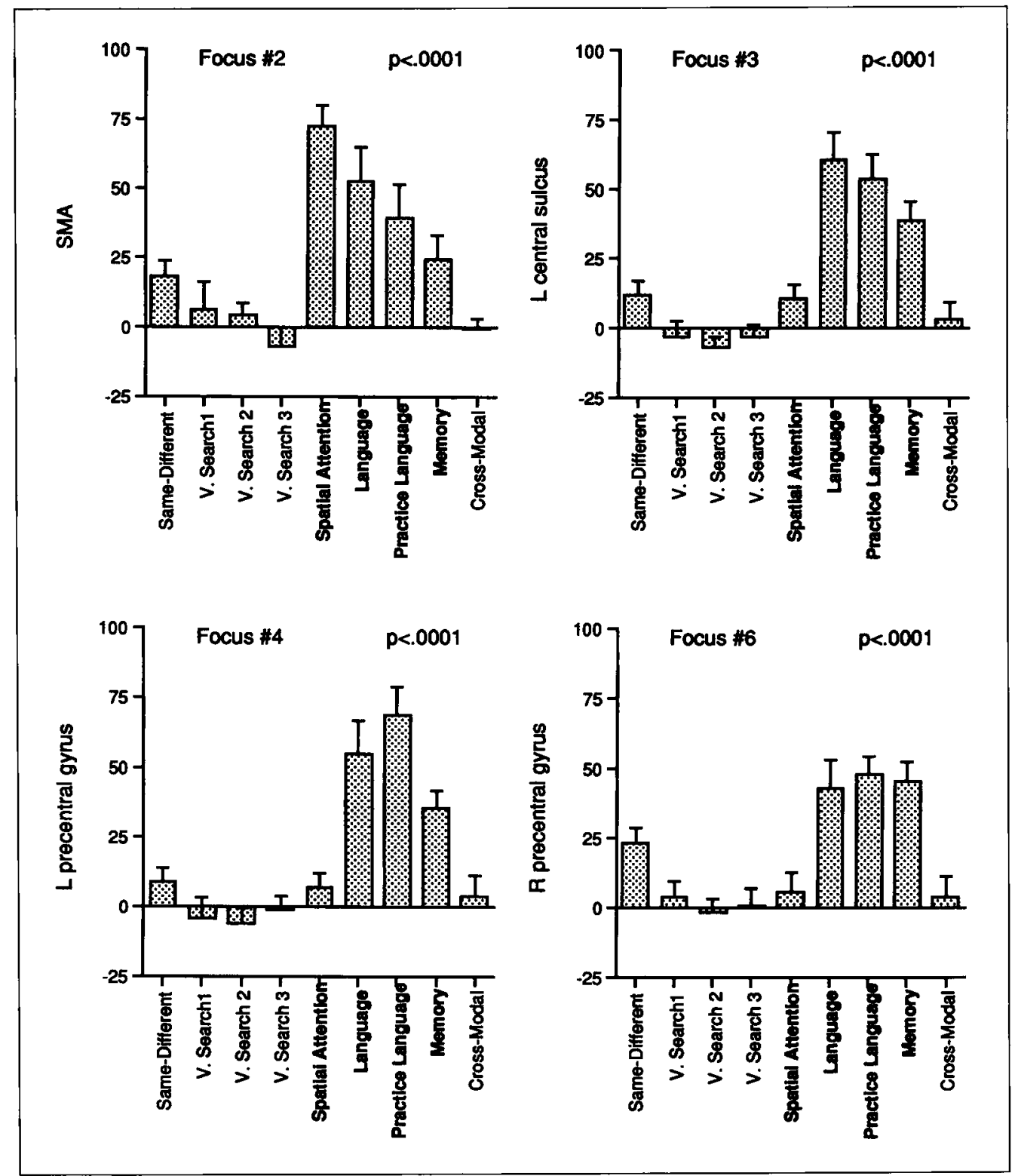

replicable subcortical foci (Figure 1). The next set of analyses assessed the consistency across experiments of these increases.

\section{Cortical Foci}

Figures 2 and 3 show the increases (in PET counts) across experiments for the seven generate plus test foci from Table 3, plus a well-sampled SMA focus from the generate megaimage that had merged in the generate plus test group with a more superior, poorly sampled focus. The four blood flow increases in Figure 2 reflected motor-related processes and were not consistent across experiments. Three areas, the left central sulcus and left and right precentral gyrus, only showed increases when the active task involved a vocal response (with no re- sponse in the passive), while the SMA showed increases during tasks involving either vocal (Language, Practice Language, Memory) or manual responses (Spatial Attention). None of the remaining four foci showed good consistency across experiments. Figure 3 shows the increases across experiments in left superior precentral gyrus, left premotor cortex (BA 6), and left (BA 44) and right (BA 44/45) frontal cortex. Perhaps the most consistent increase occurred in right frontal cortex (BA 44/45). This focus, however, did not replicate, and in four of the nine experiments, the blood flow changes were within 1 standard error of zero.

The inconsistency across experiments of the observed blood flow changes in the overall megaimage was confirmed by a 1-factor between subjects ANOVA, with Experiment as the factor. The analysis yielded significant 
Figure 3. Each graph shows the active minus passive magnitude (in PET counts) across experiments at a single focus defined by the overall megaimage. See Figure 2 caption for details.

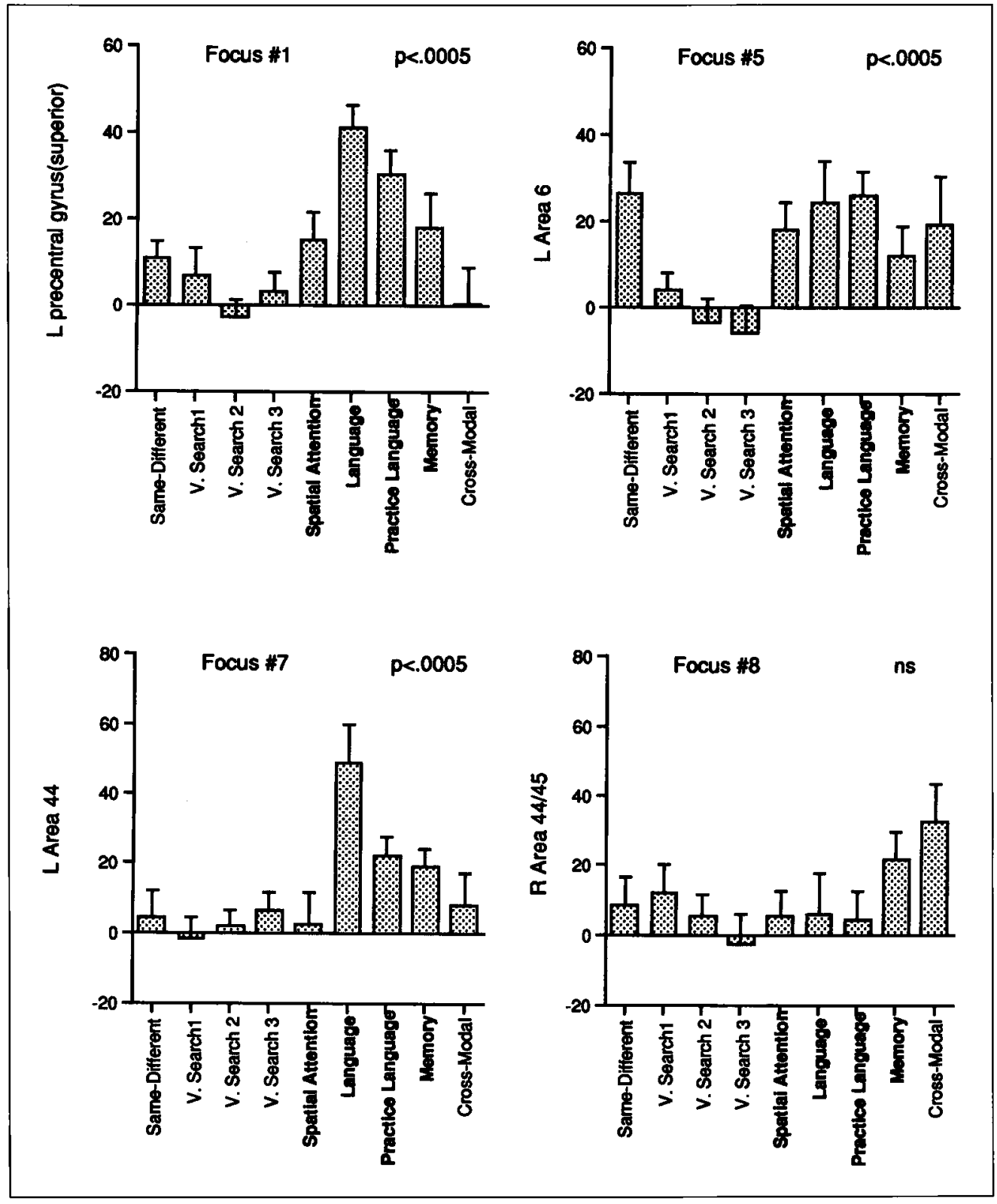

differences between experiments for six of the seven generate plus test foci from Table 3, as well as for SMA (the $p$ value for this ANOVA is shown in Figures 2 and $3)$. The only nonsignificant effect in the ANOVA occurred for the focus in right frontal cortex (BA 44/45).

This absence of cortical foci that were consistent across experiments might reflect several artifacts. First, motor-related blood flow changes in the overall megaimage, such as SMA, might have masked nonmotor-related foci in adjacent cortical areas, such as the anterior cingulate. This possibility was tested with a "matchedmotor" megaimage that combined the five experiments in which the motor demands of the active and passive conditions were equivalent (Table 1), eliminating motor- related increases. ${ }^{3}$ Any masked foci should have been revealed in the matched-motor megaimage, but no foci were observed that generalized over tasks.

Second, in four of the nine studies, subjects in the passive condition responded on each trial to control for motor-related foci in the active tasks. The passive condition therefore became an "active" task in which subjects detected the presence of a stimulus and then pressed a key. Although these task requirements were minimal, they may have masked blood flow increases in the active conditions that generalized over task. An analysis was therefore restricted to the five studies in which no response was made in the passive condition, forming a "no response in passive" megaimage. No cortical 
Figure 4. Each graph shows the active minus passive blood flow increases (in PET counts) across experiments at a replicated cerebellar focus from the overall megaimage. See Figure 2 caption for details.

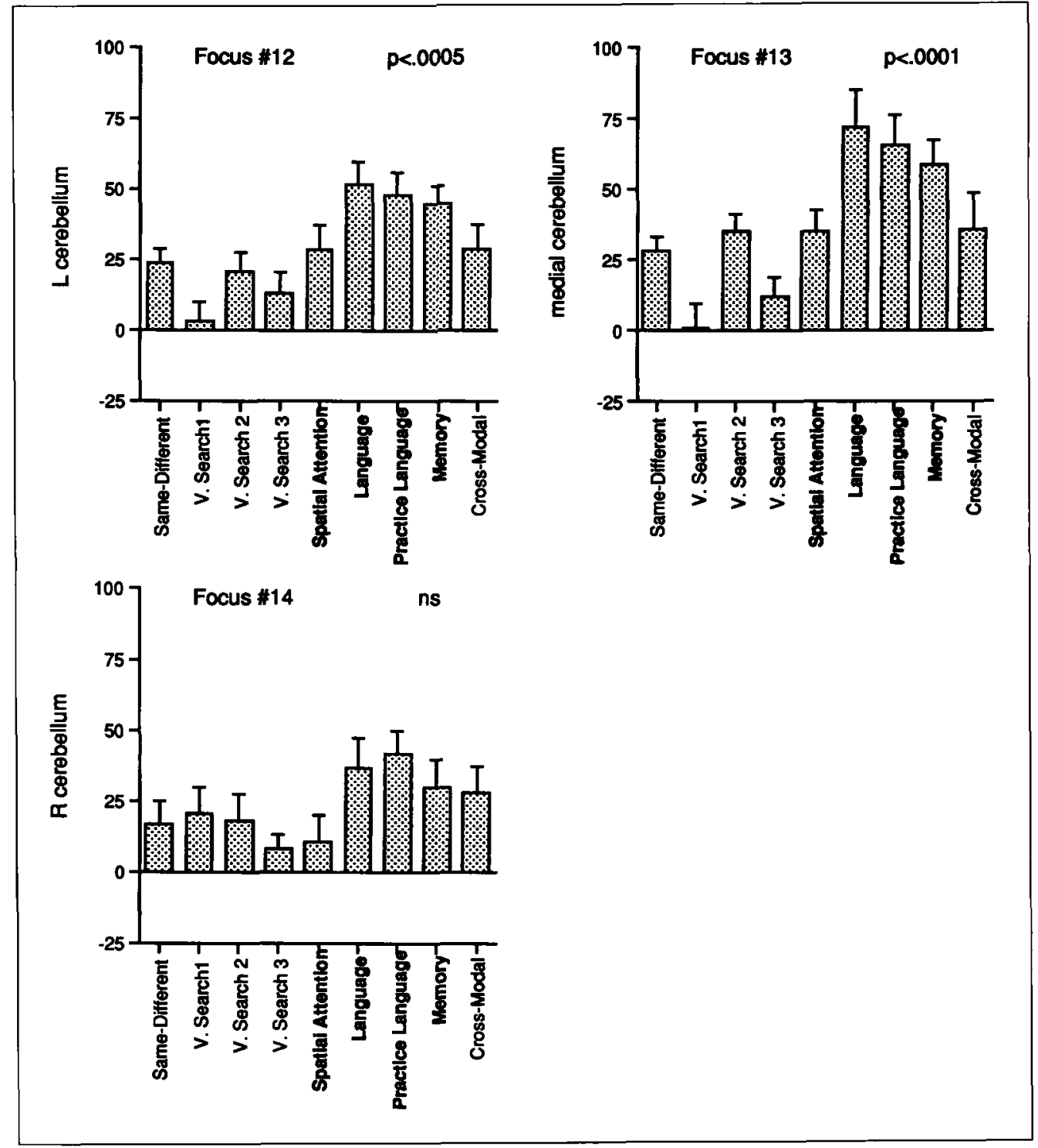

foci were found, other than those already described above.

\section{Subcortical Increases}

Figure 4 shows the active minus passive magnitudes at each experiment for the three cerebellar foci. A 1-factor ANOVA yielded highly significant differences at the medial and left cerebellar foci. Significant experimentexperiment contrasts (Table 4) largely reflected greater increases in the three language experiments that involved a vocal response in the active task and no response in the passive condition. In several cases, experiments in which the same overt response was made in both the active and passive conditions (e.g. Cross-Modal Imagery) showed larger increases than Visual Search 1, which did not involve any overt responses and showed no increase. The right cerebellar focus showed a more consistent magnitude profile across experiments, with no significant differences across experiments. Magnitudes in Visual Search 1, which did not involve any overt responses, were roughly comparable to magnitudes in many of the other experiments.

The magnitude profiles in Figure 5 suggest that the right thalamus showed the most consistent thalamic increases, but the 1-factor ANOVA yielded no significant differences across experiments at any of the foci.

In summary, several subcortical, but no cortical foci, generalized over tasks. A left and medial cerebellar foci appeared to involve motor-related processes, since increases were larger for experiments involving overt responses in the active but not passive condition, and no increase was found in Visual Search 1, which involved no overt responses. Since increases also occurred for experiments in which responses were made in both the active and passive conditions, however, these motor- 
Table 4. Significant contrasts $(p<0.05)$ between experiments for those subcortical foci yielding a significant $F$ ratio in an ANOVA comparing active minus passive increases across experiments. The numbers show the difference in active minus passive magnitudes between experiments, with the larger magnitude specified by the column experiment. For example, in the left cerebellum, the magnitude in the Practice Language (Prac.Lang.) experiment was 24 counts greater than the magnitude in the Successive Same-Different experiment (SD). SD = Successive Same-Different Discrimination, VS1-3 = Visual Search 1-3, Sp.Att. = Spatial Attention, Lang. = Language, Prac.Lang. = Practice Language, Mem $=$ Memory, Cross-modal $=$ Cross modal Imagery. Experiments in bold type involved a motor response in the active conditions but no response in the passive conditions. These experiments, particularly the three involving a vocal response (Lang., Prac.Lang, and Mem.), often showed greater blood flow than experiments in which the motor requirements of the active and passive conditions were the same (regular type).

\begin{tabular}{|c|c|c|c|c|c|c|c|c|c|}
\hline \multirow[b]{2}{*}{ Area } & \multicolumn{8}{|c|}{ Experiment } & \multirow[b]{2}{*}{ Cross-Modal } \\
\hline & $S D$ & VS1 & $V S 2$ & VS3 & Sp.Att. & Lang. & Prac.Lang. & Mem. & \\
\hline \multicolumn{10}{|l|}{ L. Cerebellum } \\
\hline $\mathrm{SD}$ & & & & & & 28 & 24 & & \\
\hline VS1 & & & & & 26 & 49 & 45 & 42 & 27 \\
\hline VS2 & & & & & & 31 & 27 & 24 & \\
\hline VS3 & & & & & & 39 & 35 & 32 & \\
\hline Sp.Att. & & & & & & 23 & & & \\
\hline \multicolumn{10}{|l|}{ Lang. } \\
\hline \multicolumn{10}{|l|}{ Prac.Lang. } \\
\hline \multicolumn{10}{|l|}{ Mem. } \\
\hline Cross-Modal & & & & & & 23 & & & \\
\hline \multicolumn{10}{|c|}{ Medial Cerebellum } \\
\hline SD & & & & & & 44 & 38 & 31 & \\
\hline VS1 & & & 33 & & 33 & 71 & 65 & 58 & 35 \\
\hline VS2 & & & & & & 37 & 32 & & \\
\hline vs3 & & & & & & 60 & 54 & 46 & \\
\hline Sp.Att. & & & & & & 38 & 32 & 24 & \\
\hline \multicolumn{10}{|l|}{ Lang. } \\
\hline \multicolumn{10}{|l|}{ Prac.Lang. } \\
\hline \multicolumn{10}{|l|}{ Mem. } \\
\hline Cross-Modal & & & & & & 36 & 30 & & \\
\hline
\end{tabular}

related processes did not only involve simple response execution. A right cerebellar focus appeared to involve nonmotor processes, since the presence or absence of an overt response in the active or passive tasks did not significantly affect blood flow.

\section{Single-Process Analyses}

Since the above analyses suggested that several subcortical foci generalized over experiments, the consistency of these foci across broadly defined processes (e.g., language-related or nonlanguage processes) was examined. Four megaimages were constructed from subsets of ex- periments in which a particular process was absent or present (Table 5):

1. A matched-motor megaimage, consisting of all experiments in which the overt motor demands of the active and passive conditions were the same. Any increase in the overall megaimage that was also present in the matched-motor megaimage could not have been caused solely by processes related to simple motor execution.

2. An unmatched-motor megaimage, consisting of all experiments in which overt responses were made in the active but not passive condition.

3. A nonlanguage megaimage, consisting of all the 
Figure 5. Each graph shows the active minus passive blood flow increases (in PET counts) across experiments at a replicated thalamic focus from the overall megaimage. See Figure 2 caption for details.

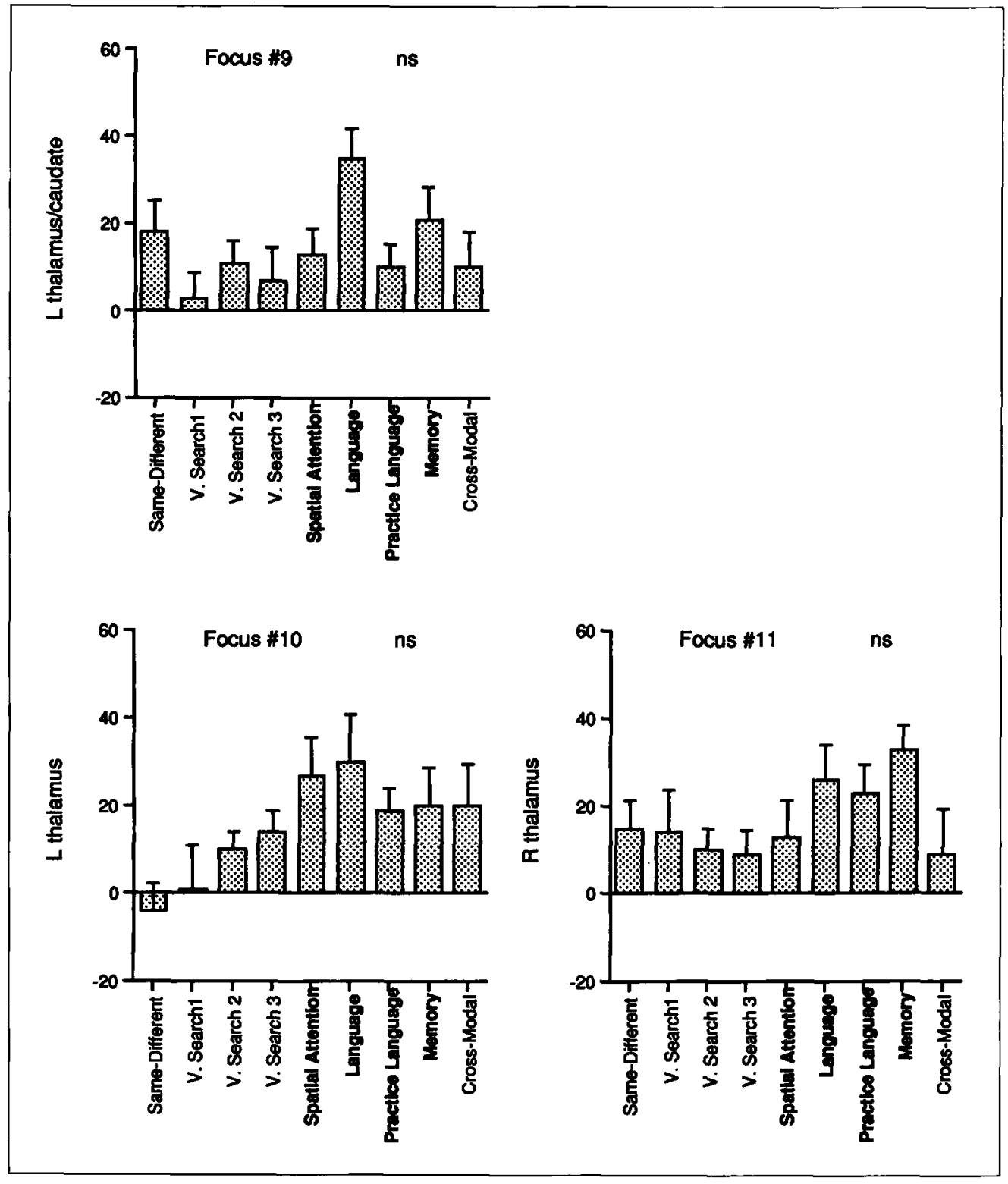

nonlanguage experiments. Increases in the overall megaimage that were also present in the nonlanguage megaimage could not have been caused solely by language-related processes.

4. A Ianguage megaimage, consisting of all the language-related experiments.

Increases were present at all subcortical foci from the overall megaimage in all four megaimages (the left thalamic increase was modest in the matched-motor megaimage but replicated when a separate replication analysis was applied to that megaimage), indicating that these foci did not require the engagement of processes specific for language, nonlanguage, or simple motor execution. ${ }^{4}$

Increases at many foci were larger for experiments involving a language or motor factor (the last column of Table 5 shows the results of an unpaired $t$ test comparing the magnitudes in the relevant megaimages), with particularly strong effects at the medial and left cerebellum foci, but these between-experiments comparisons must be treated cautiously. The experiments in the dataset differed along a number of variables that were often correlated. Three of the four experiments that included overt responses in the active but not passive condition, for example, also involved language-related tasks. Similarly, the language-related experiments all involved foveal stimuli, while the nonlanguage experiments involved large-field, parafoveal, or peripheral stimuli. In addition to these confounds, post-hoc contrasts are only warranted for those foci showing significant differences in the overall ANOVA. 
Table 5. Sample sizes, magnitudes, and $z$-scores for blood flow increases at the overall megaimage foci for those experiments that involved a response in the active but not passive condition (Unmatched-motor) or the motor requirements of both conditions were the same (Matched-motor) or which involved language-related (Language) or nonlanguage-related (Nonlanguage) processes. The last column shows the two-tailed $p$ value for an unpaired $t$ test comparing the magnitudes of the increases for the unmatched- and matched-motor experiments and the language and nonlanguage experiments.

\begin{tabular}{|c|c|c|c|c|c|c|c|}
\hline \multirow[b]{2}{*}{ Area } & \multicolumn{3}{|c|}{ Unmatched-motor } & \multicolumn{3}{|c|}{ Matched-motor } & \multirow[b]{2}{*}{ p value } \\
\hline & $N$ & Mag. & $\mathrm{z}$-score & $N$ & Mag. & $\mathrm{z}$-score & \\
\hline L thalamus/caudate & 67 & 19 & 4.94 & 65 & 9 & 2.94 & $<0.05$ \\
\hline L thalamus & 67 & 24 & 4.81 & 65 & 9 & 2.60 & $<0.02$ \\
\hline $\mathrm{R}$ thalamus & 67 & 24 & 5.90 & 65 & 11 & 3.20 & $<0.01$ \\
\hline L cerebellum & 57 & 43 & 7.79 & 56 & 19 & 4.95 & $<0.0001$ \\
\hline Medial cerebellum & 65 & 56 & 8.21 & 64 & 22 & 4.92 & $<0.0001$ \\
\hline \multirow[t]{2}{*}{ R cerebellum } & 50 & 31 & 5.29 & 47 & 18 & 4.24 & $<0.05$ \\
\hline & \multicolumn{3}{|c|}{ Language } & \multicolumn{3}{|c|}{ Nonlanguage } & \\
\hline Area & $N$ & Mag. & $\mathrm{z}$-score & $N$ & Mag. & z-score & $p$ value \\
\hline L thalamus/caudate & 62 & 19 & 4.61 & 70 & 10 & 3.35 & $=0.053$ \\
\hline $\mathrm{L}$ thalamus & 62 & 22 & 4.40 & 70 & 11 & 3.15 & $=0.07$ \\
\hline $\mathbf{R}$ thalamus & 62 & 25 & 5.61 & 70 & 12 & 3.52 & $<0.05$ \\
\hline L cerebellum & 55 & 43 & 7.84 & 58 & 19 & 4.94 & $<0.0001$ \\
\hline Medial cerebellum & 60 & 58 & 7.77 & 69 & 23 & 5.59 & $<0.0001$ \\
\hline $\mathbf{R}$ cerebellum & 51 & 34 & 5.83 & 46 & 14 & 3.59 & $<0.005$ \\
\hline
\end{tabular}

\section{Within-Experiment Analyses}

Analyses were conducted to determine whether the subcortical blood flow increases at the megaimage foci significantly varied across the conditions within each experiment (Table 6). No significant effects were found in the left cerebellum. The medial cerebellum showed larger increases during a task in which subjects searched for a conjunction of color and form than when the search was based only on color. This effect, however, was artifactual and reflected the spread of activity from nearby occipital cortex, which showed stronger increases during the conjunction task.

The right cerebellar and left thalamic regions showed significant effects on the same variables. Active minus passive magnitudes were larger in both areas during the verb-generation task, in which subjects saw a noun and said an appropriate verb (book-read), than the read task, in which subjects read the noun. Magnitudes were also larger for both regions when subjects shifted their attention in the right rather than left visual field. This latter effect was weak and reflected a small blood flow in- crease for the right visual field and a small decrease for the left visual field.

The right thalamic focus showed significant effects on a completely different set of variables. Increases were larger for a task involving the detection of a conjunction of motion and color features rather than the features in isolation and were larger during a task involving a fine shape discrimination. Increases were also larger when subjects completed word stems that began previously seen letter strings.

These results support the suggestion that the right cerebellar focus functionally differed from the left and medial cerebellar foci. The significant effects for the right cerebellum occurred between conditions in which the motor response was held constant, while these effects were not found for the medial and left cerebellar foci. The similar effects for the left thalamic and right cerebellar focus indicate a functional similarity that might reflect a functional connectivity, while the complete separation between the variables producing effects in the left and right thalamus indicate that they mediate different functions. 
Table 6. Within-experiment comparisons passing a $p$ value threshold of 0.025 at coordinates from the overall megaimage. $P$ values for marginal comparisons are shown with an $=$ sign. $F$ tests were conducted for factors with three conditions. If the test was significant, individual contrasts were evaluated. Significant contrasts are listed in the table with the appropriate $F$ statistic. Test statistics with a superscript ${ }^{\text {a }}$ were evaluated using a $50 \%$ sampling criterion.

\begin{tabular}{|c|c|c|c|c|c|c|c|c|}
\hline Area & Experiment & Condition 1 & Condition 2 & Mag. 1 & Mag. 2 & Diff. & Statistic & $p$ value \\
\hline $\begin{array}{l}\text { Medial } \\
\text { cerebellum }\end{array}$ & $\begin{array}{l}\text { Visual } \\
\text { Search } 2\end{array}$ & Color-form & Color & 53 & 12 & 41 & $t(12)=6.77$ & $<0.0001$ \\
\hline R cerebellum & $\begin{array}{l}\text { Language }+ \text { Practice } \\
\text { Language }\end{array}$ & Generate & Read & 65 & 14 & 51 & $t(17)=5.85$ & $<0.0001$ \\
\hline R cerebellum & Spatial Attention & Right field & Left field & 15 & -17 & 32 & $t(9)=2.74^{\mathrm{a}}$ & $<0.025$ \\
\hline $\mathrm{L}$ thalamus & $\begin{array}{l}\text { Language }+ \text { Practice } \\
\text { Language }\end{array}$ & Generate & Read & 27 & 3 & 24 & $t(19)=4.02$ & $<0.0005$ \\
\hline L thalamus & Spatial Attention & Right field & Left field & 47 & 6 & 41 & $t(10)=2.23$ & $=0.05$ \\
\hline $\begin{array}{l}\text { L. thalamus/ } \\
\text { caudate }\end{array}$ & Visual Search 3 & Color & Motion & 21 & -5 & 26 & $F(1,20)=7.59$ & $<0.025$ \\
\hline \multirow[t]{2}{*}{$\mathrm{R}$ thalamus } & Visual Search 3 & Conjunction & Motion & 18 & -1 & 19 & $F(1,20)=5.46$ & $=0.03$ \\
\hline & & Conjunction & Color & 18 & -3 & 21 & $F(1,20)=6.50$ & $<0.025$ \\
\hline \multirow[t]{3}{*}{$\mathrm{R}$ thalamus } & Same-Diff. & Shape & Color & 36 & 8 & 28 & $F(1,24)=5.54$ & $=0.027$ \\
\hline & & Shape & Motion & 36 & 6 & 30 & $F(1,24)=6.73$ & $<0.025$ \\
\hline & & Shape & Divided & 36 & -5 & 41 & $F(1,24)=12.2$ & $<0.005$ \\
\hline \multirow[t]{2}{*}{$\mathrm{R}$ thalamus } & Memory & Priming & Baseline & 41 & 16 & 25 & $F(1,16)=9.9$ & $<0.01$ \\
\hline & & Memory & Baseline & 42 & 16 & 26 & $F(1,16)=11.1$ & $<0.005$ \\
\hline
\end{tabular}

\section{Correlations between Foci}

For each pair of subcortical increases from the overall megaimage, the correlation was computed across the 35 different active tasks of the entire dataset. The right thalamus showed a significant correlation with the left and medial cerebellum (Table 7, Figure 6). The left thatamus showed a more modest correlation with the right and medial cerebellum, which was largely carried by the verb-generation/read variable in the Language and Practice Language experiments. Correlations between the ipsilateral thalamus and cerebellum were smaller than the contralateral correlations and were nonsignificant. The left and right thalamic loci were uncorrelated.

Significant correlations across conditions were also evident between all three cerebellar loci. The most pronounced correlation was between the medial and left cerebellar focus, but the medial focus also correlated with the right focus. The medial-lateral correlations may have been caused in part by the spread of large blood flow increases to adjacent locations. Spread, however, cannot explain the correlation between the left and right

Table 7. Correlation matrix for coordinates from the overall megaimage, where each correlation is taken across the active minus passive magnitude in each condition $(N=35)$ of the dataset.

\begin{tabular}{lccccc}
\hline & L. Cereb. & Med. Cereb. & R. Cereb. & L. Thal. & L. Thal./Caud. \\
\hline L. Cereb. & - & & & \\
Med. Cereb. & $0.83^{* * *}$ & - & & \\
R. Cereb. & $0.51^{* *}$ & $0.65^{* * *}$ & - & & \\
L. Thal. & 0.31 & $0.38^{*}$ & $0.39^{*}$ & - & - \\
L. Thal/Caud. & 0.31 & 0.25 & 0.08 & 0.06 & 0.26 \\
R. Thal. & $0.56^{* * *}$ & $0.46^{* *}$ & 0.28 & 0.07 & - \\
\hline
\end{tabular}

${ }^{*} p<0.05,{ }^{* *} p<0.005,{ }^{* * *} p<0.0005$. 


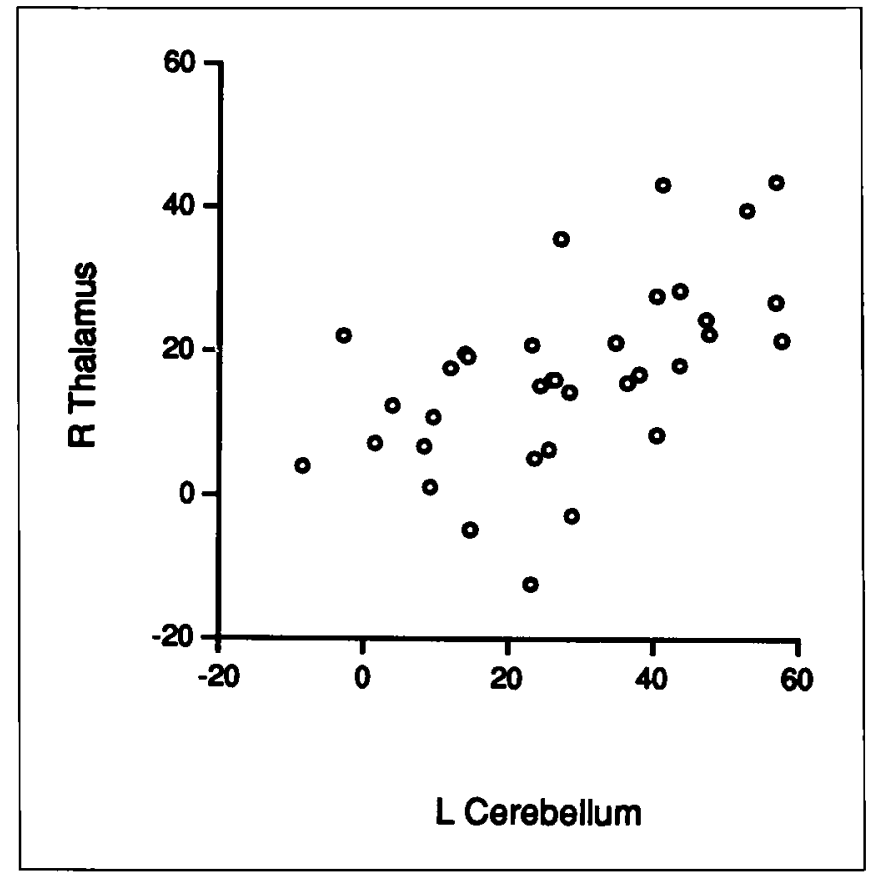

Figure 6. Scatterplot showing the relationship between magnitudes (in PET counts) at the right thalamic and left cerebellar foci. Each point represents the magnitude for a condition $(N=35)$ within an experiment, summed over subjects. cerebellar foci, which may have reflected the confounding of motor and linguistic variables across experiments. Three of the four Ianguage-related experiments involved vocal responses in the active conditions but no responses in the passive condition. The right cerebellar focus may have been increased during the languagerelated processes (as in the verb-generation task), while the left focus may have been increased by motor-related processes in the same experiments.

These correlational analyses indicated that increases in the medial and left cerebellum were functionally related to increases in the right thalamus and also supported the suggestions from the within-experiment analyses that increases in the right and left thalamus were unrelated.

\section{Passive Minus Fixation Analyses}

\section{Covert Task Processing}

Subjects may have covertly performed the active task on the displayed stimulus during the passive condition, reducing the magnitude of active minus passive increases and obscuring foci (e.g., in cortex) that generalized over tasks. This possibility was examined by analyzing the passive minus fixation scans (the stimulus was absent in fixation scans).

Table 8. Blood flow increases from the passive minus fixation megaimage. See Table 3 caption for details.

\begin{tabular}{|c|c|c|c|c|c|c|c|c|c|c|c|}
\hline \multirow[b]{2}{*}{ Area } & \multicolumn{3}{|c|}{ Generate coordinate } & \multicolumn{2}{|c|}{ Test } & \multicolumn{5}{|c|}{ Generate plus Test } & \multirow[b]{2}{*}{ z-score } \\
\hline & $X$ & $Y$ & $Z$ & Mag. & p value & $X$ & $Y$ & $Z$ & $N$ & Mag. & \\
\hline \multicolumn{12}{|l|}{ Frontal Lobe } \\
\hline L 32 (anterior cingulate) & -9 & 27 & 32 & 12 & $<0.05$ & -7 & 27 & 30 & 79 & 15 & 3.38 \\
\hline L 24 & -19 & -7 & 46 & 12 & $<0.005$ & & & & & & \\
\hline R 24 & 25 & -15 & 34 & 12 & $<0.05$ & 23 & -15 & 32 & 79 & 11 & 3.36 \\
\hline 6 (SMA) & -7 & 5 & 56 & 17 & $<0.01$ & -7 & 5 & 56 & 65 & 19 & 4.16 \\
\hline R 4 & 33 & -27 & 57 & 19 & $<0.01$ & 31 & -23 & 54 & 63 & 21 & 2.74 \\
\hline $\mathrm{L} 6$ & -29 & -1 & 58 & 2 & ns & -27 & -1 & 54 & 67 & 14 & 3.38 \\
\hline R 6 (medial frontal gyrus) & & & & & & 13 & 1 & 52 & 71 & 13 & 3.07 \\
\hline R 6 (precentral gyrus) & 39 & -9 & 54 & 11 & $<0.05$ & 37 & -9 & 48 & 75 & 15 & 3.79 \\
\hline L 45 & -51 & 23 & 4 & 11 & $<0.05$ & -49 & 23 & 12 & 79 & 13 & 2.78 \\
\hline L $47 / 10$ & -41 & 46 & -7 & 11 & ns & -41 & 47 & -2 & 57 & 11 & 2.31 \\
\hline \multicolumn{12}{|l|}{ Temporal Lobe } \\
\hline R 21 & 35 & -53 & 2 & 9 & ns & 37 & -55 & 6 & 79 & 12 & 2.81 \\
\hline \multicolumn{12}{|l|}{ Subcortical } \\
\hline $\mathbf{R}$ cerebellum & 23 & -71 & -16 & 9 & $<0.05$ & 23 & -67 & -12 & 72 & 22 & 5.10 \\
\hline $\mathrm{L}$ cerebellum & & & & & & -31 & -75 & -16 & 63 & 15 & 2.90 \\
\hline
\end{tabular}


Twenty-two well-sampled foci in cortex exceeding 10 counts were found in a generate passive minus fixation megaimage (Table 8). Two cingulate foci (left BA 32 and right BA 24) and one left frontal focus (BA 45) replicated at a 0.05 significance level (no focus survived a Bonferroni correction) and were present in the generate plus test megaimage. Several reliable foci were also found in right hemisphere motor and premotor areas presumably related to the left-hand response made in three of the seven studies. The magnitude screen for identifying additional increases yielded only one cortical focus, also in right premotor cortex (BA 6).

Any covert task processing in the passive condition was presumably less than in the active tasks. Each experiment, for example, produced substantial active minus passive increases, indicating more task-relevant activity during the active condition. If the above nonmotor, cortical increases reflected covert processing, rather than automatic processes triggered by the stimulus, then increases at these foci should also have occurred in the active minus passive megaimage. No increases were found (left BA 32, magnitude $=0$; right BA 24, magnitude $=0$; left $\mathrm{BA} 45$, magnitude $=-1$ ). These results indicate that the absence of cortical increases that generalized across tasks was not caused by covert processes in the passive condition.

\section{Effects of Simple Motor Execution}

The passive minus fixation data were also used to test whether processes related to simple motor execution could increase blood flow at the subcortical foci previously identified from the active minus passive megaimage. Although manual responses were made in the passive condition of four of the seven experiments, no responses were made in any of the fixation conditions.
A passive minus fixation megaimage from these four experiments (unmatched-motor) was compared to the passive minus fixation megaimage based on the three experiments in which no response was made in the passive (matched-motor).

Table 9 shows the magnitudes from each of these passive minus fixation megaimages at the coordinates from the active minus passive megaimage (e.g., the coordinates from Table 3 ). Between subjects $t$ tests on the response variable indicated that passive minus fixation magnitudes were significantly greater when subjects made a response in the passive condition for the medial cerebellum, left cerebellum, and left thalamus/caudate, with a marginal effect in the right thalamus. Inspection of the passive minus fixation images indicated that the peak of the passive minus fixation blood flow increases in the medial $(-13,-55,-10$, magnitude $=30, z=3.43)$ and left $(-27,-47,-14$, magnitude $=23, z=3.22 ;-19$, $-55,-26$, magnitude $=31, z=3.70$ ) cerebellar regions occurred 14 to $17 \mathrm{~mm}$ from the active minus passive increases. The passive conditions involved manual responses, while the active conditions involved a mixture of manual and vocal responses. Interestingly, however, an analysis of foci from individual experiments did not indicate any systematic differences in the location of the medial and left cerebellar increases produced by vocal or manual responses during the active tasks.

These analyses support the interpretation that the left and medial cerebellar foci were motor-related since blood flow increases at those locations could be produced simply by making a manual response. These processes were more complex than simple motor execution, however, since the peak of the blood flow increase was displaced from the active minus passive increases.

Table 9 also suggests that blood flow at the thalamic foci may have been greater during the fixation than

Table 9. Passive minus fixation magnitudes at coordinates specified by the active minus passive megaimage. The left panel shows the magnitudes in a set of passive minus fixation scans in which a response was made in the passive (Unmatched-motor). The middle panel shows the magnitudes from a set of passive minus fixation scans in which no response was made in the passive (Matched-motor). The right panel shows the results of unpaired $t$ tests comparing the magnitudes in the other two panels.

\begin{tabular}{|c|c|c|c|c|c|c|c|c|c|}
\hline \multirow[b]{2}{*}{ Area } & \multicolumn{3}{|c|}{ Unmatched-motor } & \multicolumn{3}{|c|}{ Matched-motor } & \multicolumn{3}{|c|}{ Unpaired $t$ Tests } \\
\hline & $N$ & Mag. & $z$-score & $N$ & Mag. & $z$-score & $\begin{array}{l}\text { Difference } \\
\text { Score }\end{array}$ & Statistic & $p$ value \\
\hline $\begin{array}{l}\text { L thalamus/ } \\
\text { caudate }\end{array}$ & 33 & 7 & 1.23 & 46 & -15 & -2.88 & 22 & $t(77)=2.94$ & $<0.005$ \\
\hline $\mathrm{L}$ thalamus & 33 & -7 & -1.01 & 46 & -13 & -2.20 & 6 & $t(77)=0.68$ & ns \\
\hline $\mathbf{R}$ thalamus & 33 & 1 & 0.10 & 46 & -15 & -2.73 & 16 & $t(77)=1.86$ & $=0.066$ \\
\hline L cerebellum & 31 & 21 & 3.17 & 38 & -4 & -0.88 & 25 & $t(67)=3.36$ & $<0.005$ \\
\hline Medial cerebellum & 33 & 22 & 3.01 & 44 & -13 & -2.17 & 35 & $t(75)=3.94$ & $<0.0005$ \\
\hline R cerebellum & 26 & 13 & 2.11 & 30 & 5 & 0.94 & 8 & $t(54)=1.04$ & ns \\
\hline
\end{tabular}


passive conditions. Baseline shifts between the passive and fixation conditions could be caused by covert task activity and/or automatic processing of the stimulus during the passive condition. It is not clear, however, why these processes would decrease blood flow in the passive conditions.

\section{Additional Analyses of Cerebellar Blood Flow Increases}

Since the left and medial cerebellar foci appeared to reflect complex response-related processes, analyses were conducted to assess the effects at these foci of overall reaction time and the speeded nature of the active tasks.

\section{Effect of Overall Reaction Time}

There was little evidence that reaction time predicted the magnitude of the cerebellar increases within an experiment. Reaction times were significantly longer in the verb-generation than read tasks, but increases at the two cerebellar foci were only marginally different for the two tasks (medial cerebellum: $F(1,19)=3.72, p<0.07$; left cerebellum: $F(1,19)=2.19, p>0.10)$. Reaction times were also longer in a conjunction search than feature search task, but increases for the two tasks were not different at either focus (medial cerebellum: $F(2,18)=$ 0.58 ; left cerebellum: $F(2,14)=1.18$ ).

\section{Speeded versus Unspeeded Experiments}

Time pressure was more evident in the active than passive conditions, particularly since several experiments involved explicit measurement of reaction time. Of the four experiments in which a choice manual response was made in the active task, two involved an explicit reaction time criterion (Visual Search 3, Cross-Modal Imagery), while two involved the measurement of accuracy (Successive Same-Different Discrimination, Visual Search 2). There was no evidence for larger blood flow increases in the reaction time experiments.

\section{DISCUSSION}

Active minus passive increases in cortical regions did not generalize over tasks (with the caveat that high superior parietal and inferior orbito-frontal regions were not wellsampled), but consistent increases were observed in the thalamus and cerebellum. This section first discusses possible functions of the thalamic and cerebellar foci and then considers the implications of the results for processes that generalize over tasks.

\section{Cerebellar Blood Flow Increases}

\section{Medial and Left Cerebellum}

The increases across experiments at these two foci were strikingly similar and suggested that both foci were response-related. Increases were often larger in experiments involving a vocal response in the active conditions and no response in the passive condition (Table 4) than in experiments involving the same response in both the active and passive conditions. Furthermore, no increase was seen in Visual Search 1, which involved no responses in any condition.

Two results suggested, however, that increases at these foci were not related to simple motor execution. First, passive conditions involving a manual response produced passive minus fixation foci that were displaced from the active minus passive foci. The medial cerebellar focus from the passive minus fixation megaimage, for example, was more anterior and lateral than the active minus passive focus and was very similar to that reported by Fox, Raichle, and Thach (1985) for finger movements. Simple motor movements produced foci displaced from the active minus passive foci.

Second, active minus passive increases were present under conditions in which the same motor response was made in the active and passive conditions. ${ }^{5}$ Interestingly, the one experiment in which a manual response was made in the active but not passive condition (Spatial Attention) yielded blood flow increases roughly equivalent to those in which manual responses were made in both conditions (Figure 4 ). The standard motor control of requiring a keypress in the passive condition did not eliminate motor-related increases at these cerebellar loci.

Motor-related factors involved in preparing speeded responses or long-latency responses did not account for the data. Increases were similar in experiments that measured reaction time or accuracy, while within-experiment analyses yielded little evidence that increases were affected by overall reaction time. The greater complexity of the response selection process in the active than passive conditions might account for the increases, although a PET study of response-selection (Deiber et al., 1991) did not report cerebellar changes with stimulusresponse mappings of different complexity (e.g., push a joystick forward in response to a tone versus push the joystick in one of four directions, depending on which of four tones was presented).

Several authors have suggested that the structure of the cerebellum is well-suited for associating movements with particular contexts (Albus, 1971; Marr, 1969). Although these contexts are sometimes considered in motor terms, as in sequential movements, the contexts may also be stimulus-related (Thach, 1996; Thompson, 1990). An explicit associative role for the cerebellum has been suggested, for example, by studies of classical conditioning (Thompson, 1990). The cerebellum may be involved in some aspects of response-selection. 


\section{Rigbt Cerebellum}

The results for the right cerebellum were very different from those for the medial and left cerebellum and suggested a role in nonmotor processes. The between-experiments ANOVA was not significant. Visual Search 1, which did not involve any overt responses, produced increases of roughly the same magnitude as the other nonlanguage experiments, and there was no significant difference in the passive minus fixation subtraction between passive conditions that did or did not involve a response. Furthermore, the within-experiment effects for the right cerebellar focus concerned conditions that involved the same motor response (e.g., the read and verb-generation tasks, left and right visual field conditions), and these effects did not occur for the left and medial cerebellar foci. While the location of the left cerebellar focus was consistent with the intermediate cerebellar region, the right cerebellar focus plotted more laterally in the cerebellar hemisphere. Anatomical connections (Middleton \& Strick, 1994), lesion-behavior correlations (Akshoomoff, Courchesne, Press, \& Iraqui, 1992; Fiez, Petersen, Cheney, \& Raichle, 1992; Ivry \& Keele, 1989), and neuroimaging studies (Kim, Ugurbil, \& Strick, 1994; Petersen, Fox, Posner, Mintun, \& Raichle, 1989; Raichle et al., 1994) suggest that the lateral cerebellar hemispheres are involved in some nonmotor tasks (Leiner, Leiner, \& Dow, 1993).

Although there was some suggestion that the right cerebellar increase was greater for language-related processes (while the between-experiments ANOVA was not significant, increases were larger in the four languagerelated experiments), this focus was clearly modulated by nonlanguage processes. When the five nonlanguage experiments were combined into a nonlanguage megaimage, an increase was observed at the overall megaimage focus (Table 5) as well as a nearby focus in the nonlanguage megaimage $(27,-57,-22 ; z=4.09)$. Although it is possible that the language and nonlanguage experiments increased different regions of the right cerebellum, an analysis of the foci from individual experiments indicated no obvious clustering of the two groups. While we cannot say that the same region or sets of neurons were involved in language and nonlanguage tasks, both types of tasks increased similar cerebellar regions.

Several authors have suggested roles for the cerebellum in cognitive processes that generalize over tasks (Akshoomoff \& Courchesne, 1994; Fiez et al., 1992; Keele \& Ivry, 1991). Fiez et al. have proposed, for example, that the cerebellum is involved in error detection/error checking, while Akshoomoff and Courchesne have suggested that the cerebellum is involved in switching from one task to another or to different components of a task. It is also possible that the cerebellum may have multiple uses depending on the current task environment. A re- gion that plays one role during verbal tasks may play a completely different role during nonverbal tasks.

\section{Thalamic Blood Flow Increases}

The thalamus contains many nuclei with distinct functions that are spatially adjacent. It is therefore difficult to assign a single function to a megaimage increase, since it may sum increases from adjacent nuclei that are engaged in different conditions.

\section{Left Thalamus}

The left thalamus showed no significant differences across studies. As with the right cerebellum, larger increases were found for the verb-generation than read task in the Language and Practice Language experiments and for the right than left visual field in the Spatial Attention experiment. Since lesions of the left thalamus can produce aphasia (Graff-Radford, Damasio, Yamada, Eslinger, \& Damasio, 1985; Kirk \& Kertesz, 1994; Perani, Vallar, Cappa, Messa, \& Fazio, 1987), the verb-generation/read effect is plausibly related to language processing. The visual field effect is consistent with a contralateral field representation.

Although the visual field and language effects may have been mediated by different nuclei, an analysis of foci from individual conditions indicated that the right visual field focus $(-3,-13,12)$ was very near the verbgeneration focus $(-7,-17,16)$. Both plotted in the dorsomedial nucleus, which projects to frontal cortex, but this localization is necessarily tentative. No common frontal increases were found for the two conditions, but thalamic inputs to frontal cortex are probably task contingent.

\section{Right Thalamus}

The profile of right thalamic increases across experiments was fairly consistent, with no significant differences in the between-experiments ANOVA. The right thalamus showed significant differences on an entirely different set of within-experiment variables than the left thalamus, with effects in experiments involving visual discriminations and memory. The independence of the two thalamic regions was also apparent from their very low correlation across conditions. The blood flow increase in the right thalamus was spatially extended (Figure 1), suggesting that several nuclei may have contributed to the observed increase. Two foci were found in the generate megaimage but merged in the generate plus test megaimage.

Both the consistency of the increases across experiments and the nature of the within-experiment effects are compatible with a role of the right thalamus in attentional engagement of visual stimuli. Right thalamic 
increases were particularly large during the shape condition of the Same-Different Discrimination experiment, which probably required focal attention to shapes in the display. Larger increases were also found in the conjunction condition of Visual Search 3, which emphasized focal attention to a restricted spatial region. A recent analysis of the data from Visual Search 3 (Corbetta, Shulman, Miezin, \& Petersen, 1995) found increased right parietal activity during the conjunction task, consistent with a greater frequency of shifts of attention. Right thalamic lesions can produce spatial neglect (Vallar \& Perani, 1987) and Laberge and Buchsbaum (1990) have reported right thalamic activity during an attentional filtering task. Rafal and Posner (1987) have proposed a role for the thalamus in engaging spatial attention at a spatial locus, consistent with the present results.

\section{Relationships between Cerebellar and Thalamic Blood Flow Increases}

A significant correlation across conditions was found between the right thalamic and left and medial cerebellar foci, while nonsignificant correlations were observed with the ipsilateral foci. Although this correlation corresponds to the crossed anatomical relationships between these structures, with cerebellar nuclei projecting to contralateral thalamus, it may simply reflect functional similarities.

The profile of right thalamic increases across experiments was fairly consistent, with no significant effect in the between-experiment ANOVA, but magnitudes were larger in those experiments involving a vocal response. To the extent that these experiments, which had a strong motor component, were also more difficult or required greater attention, this correlation is consistent with an attentional function for the right thalamus. We suggest, however, that motor-related processes in the right thalamus were responsible for the correlation. A small response component to the right thalamic focus is consistent with the marginal effect of response in the passive minus fixation subtraction. Furthermore, since overt motor factors varied between experiments but not within experiments, a motor interpretation of the correlation is consistent with the absence of common within experiment variation at the two foci. Motor processes mediating the left and medial cerebellar foci (which showed a smaller but significant correlation) may have involved projections to motor nuclei in the right thalamus.

The modest correlation between the left thalamus and right cerebellum was primarily carried by the verbgeneration/read variable, which produced a significant effect in the within-experiment ANOVAs. Left frontal cortex, left thalamus, and right cerebellum may form a circuit in certain language tasks. Both foci also showed the same effect of the visual field variable in the Spatial Attention experiment.

\section{Processes Common to Active Tasks}

Although most tasks involve increases in arousal, establishing an intention or behavioral goal, setting up control structures for sequencing task operations, detecting targets, etc., these operations do not produce blood flow increases, detectable with the present methods, in localized cortical regions that are common across tasks. Common subcortical regions, however, may be involved.

\section{Arousal}

It seems plausible that the level of arousal was greater during active than passive conditions, although we do not have independent evidence of this. Subcortical regions, including the reticular formation, brainstem nuclei involved in the control of monoamine systems, and diffuse thalamic nuclei, are often considered to be involved in setting arousal levels. The present analysis did not find any brainstem regions that generalized over task, but the thalamic increases may have been arousal-related. PET (Pardo et al., 1991) and lesion studies (Ladavas, 1987; Posner et al., 1987) have also implicated the cortex of the right hemisphere in the maintenance of sustained attention, but no evidence was found for a consistent cortical locus underlying any active minus passive arousal differences.

\section{Task Preparation and the $C N V$}

With long intervals $(>3 \mathrm{sec}$ ) between a warning signal and an imperative stimulus, a CNV can be measured that has both an initial component, related to the warning signal, and a terminal component. There is controversy concerning whether the terminal component is strictly related to response factors (Brunia \& Damen, 1988; Ruchkin, Sutton, Mahaffey, \& Glaser, 1986). Although a separate warning signal was not given in the present studies, the fixed, although relatively short ( 1 to $2 \mathrm{sec}$ ), intertrial interval in all studies should have enabled the development of a prepatory state involving motor and perhaps nonmotor components. Foci in the SMA, central sulcus, precentral gyrus, BA 6, and BA 44 from the present study may mediate the motor readiness components of the CNV (Deiber, Ibanez, Sadato, \& Hallett, 1996; Singh \& Knight, 1990), as well as response selection and execution. These foci were Iargely eliminated (aside from the BA 6 focus) when the motor requirements of the active and passive task were equated in the matchedmotor megaimage. Since any nonmotor components of the CNV should have been present in the overall megaimage, the present results imply that cortical generators for these components shift with task demands. The observed increases in the thalamus, however, may be linked to the CNV (Tsubokawa \& Moriyasu, 1978).

Two factors complicate the interpretation of the present results with respect to the CNV. First, the control 
state for the CNV is the intertrial interval preceding the warning signal, rather than a separate passive condition. Second, the normalization used to correct for changes in global blood flow eliminates any absolute increase in blood flow that might be produced by arousal or task preparation (although there is no evidence that active task states produce global increases (Sokoloff, Mangold, Wechsler, Kennedy, \& Kety, 1955).

\section{Attention: Sources of Interference}

Attention refers in part to limitations in our ability to perform simultaneous activities (Broadbent, 1958). The performance of most active tasks can interfere with the performance of other ongoing activities or tasks, a phenomenon known as dual-task interference. Although interference may occur because all tasks require the use of some general structure or resource (Posner, 1978), dual-task interference also probably has multiple "local" causes that depend on the specific task-pairings that are studied (McLeod, 1978). Tasks involving visual stimuli, for example, may interfere because of competition for structures within the visual system (Desimone \& Duncan, 1995; Treisman \& Davies, 1973). It is unclear if interference would be found between most tasks in the present dataset if local perceptual/motor sources of interference were removed.

\section{Attention: Mechanisms of Interference}

The simplest idea is that interference between two tasks results when both tasks use the same set of neurons. The current analysis suggests that if tasks interfere because they all require use of a general structure or resource (see above), that structure is not localized in cerebral cortex. There was no evidence, for example, of common active minus passive blood flow increases in the anterior cingulate, which has been suggested as mediating a general process of target detection that is common to most tasks (Posner \& Petersen, 1990). Any general source of interference within the visual system also does not appear to be highly localized. No consistent increases were found in inferotemporal and parietal regions that form the later stages of the ventral and dorsal processing streams (Van Essen \& DeYoe, 1995). Thalamic nuclei may serve a selective function by restricting the input to a given process (Crick, 1984; Olshausen, Anderson, \& Van Essen, 1993; Skinner \& Yingling, 1977), but it is unclear if thalamic circuitry imposes any inherent limitations on the type of inputs that can be simultaneously selected.

Although common use of the same set of neurons may explain dual-task interference in some situations, other neural mechanisms are possible. A set of neurons that is active during one task, for example, might inhibit another set of neurons involved in a different task, or the two sets of neurons might produce destructive cross-talk (Allport, 1989). Any source of interference that is medi- ated by interactions between different parts of a region (e.g., different parts of a topographically organized area; Desimone \& Duncan, 1995) might not be revealed as a common blood flow increase. This might apply, for example, to the anterior cingulate.

\section{Task Memory/Control}

Each active task involved a structured sequence of events in which operations needed to be conducted in a particular order. Although various processes may have also occurred during the passive state (Shulman, Fiez, et al., 1997), they did not have an obligatory ordering or sequence. It is possible that these sequential events were stored in a common task memory and that control signals were necessary to ensure that processes were executed in the correct order. Although these processes do not appear to be localized in a single cortical area, Akshoomoff and Courchesne (1994) have suggested that the cerebellum might be involved in switching between different components of a task. Structures for task memory and control might be difficult to detect with the present PET paradigms. Since tasks were blocked, these structures could be established at the beginning of the block without being reset each trial.

\section{METHODS}

The analysis involved ten experiments, all of which have been published in some form. Two experiments were virtually identical and have been collapsed. All nine studies involved comparisons between active tasks in which subjects made judgments based on a visual stimulus while maintaining fixation on a central cross and passive tasks in which the same or very similar stimulus was presented, but subjects were simply instructed to remain fixated on the cross. In some passive conditions, subjects also made a motor response (e.g., pressing a key) on each trial (Table 1). The term passive therefore refers to the fact that subjects did not make a discrimination based on the displayed stimulus. Studies primarily differed in the nature of the stimulus displays and the tasks performed on those displays (Table 2). Informed consent for subjects in all studies was obtained prior to participation following guidelines approved by the Human Studies Committee and the Radioactive Drug Research Committee of Washington University.

\section{PET Methodology}

The general PET methodology for all experiments was similar. Experiments were conducted on a PETT VI tomograph (Ter-Pogossian, Ficke, Hood, Yamamoto, \& Mullani, 1982; Yamamoto, Ficke, \& Ter-Pogossian, 1982), which provides seven transverse slices with a $14.4-\mathrm{mm}$ interslice distance. During PET scans, earplugs were inserted to dampen background noise, and a molded plas- 
tic facial mask was fitted to each subject's head to reduce movement (Fox, Perlmutter, \& Raichle, 1985). Stimuli were presented on a color monitor positioned roughly 40 to $50 \mathrm{~cm}$ from the subject, and a black cloth was placed around the monitor to reduce extraneous visual input. The experimental room lights were dimmed during scans. Cooling fans and the scanner itself provided low-level background noise. All displays involved a central fixation cross, and EOG was monitored in most conditions.

${ }^{15} \mathrm{O}$ labeled water (half-life of $123 \mathrm{sec}$ ) was used as a blood-flow tracer and administered as an intravenous bolus injection. The number of scans varied across study, with at least a 10-min delay between scans to allow complete decay of ${ }^{15} \mathrm{O}$. The PETT VI system was used in the low-resolution mode. Images were reconstructed to 17-mm full width at half-maximum using filtered backprojection (Yamamoto et al., 1982). Since blood-flow increases are known to be a linear function of radiation counts for scans of less than 1-min duration, measurements of arterial blood radioactivity following ${ }^{15} \mathrm{O}$ injection were not made (Fox, Mintun, Raichle, \& Herscovitch, 1984; Herscovitch, Markham, \& Raichle, 1983).

All PET images were normalized by linear scaling for global blood flow so that fluctuations in global blood flow would not obscure local changes induced by task manipulations (Fox, Miezin, Allman, Van Essen, \& Raichle, 1987). A lateral skull x-ray, taken during the PET session, was used to identify the glabella and inion as markers to locate the position of the transverse plane intersecting the anterior and posterior commissures (Fox, Perlmutter, et al., 1985; Talairach, Szikla, \& Tournoux, 1967). Each image was then transformed into a standardized stereotaxic space (Talairach \& Tournoux, 1988), with voxels measuring $2.0 \times 2.0 \times 2.0 \mathrm{~mm}$.

\section{Studies}

Although each experiment differed in many characteristics, they fell into broadly defined categories. Experiments 1 through 4 did not involve any linguistic processes, and motor demands were similar in both the active and passive conditions (e.g., either both or neither active and passive conditions involved a keypress response, Table 1), while Experiments 6 through 8 involved language-related processing with vocal responses in the active tasks and no responses in the passive tasks. The term language-related is purposely vague. While the input (a letter string) and output (a vocal response) characteristics of Experiments 6 through 8 were similar, the intermediate processes related to the selection of an appropriate response were very different. Experiments 5 and 9 mixed the motor and language factors. Experiment 5 did not involve language and did not require a response in the passive condition. Experiment 9 involved language and required a keypress in both the active and passive conditions.

\section{Averaging of Scan Pairs}

The analyses in this paper combined data from the different conditions and subjects within an experiment and also combined data from different experiments.

\section{Averaging of Scan Pairs within an Experiment}

Since scan pairs from subjects were sometimes missing or not analyzed for technical reasons, the total number of scan pairs from each subject generally differed, and the total number of scan pairs from each active condition of an experiment also generally differed. Scan pairs were therefore weighted to satisfy two constraints that eliminated these differences: (1) The active minus passive scan pairs from the different active conditions for a subject were weighted so that when summed across condition, each subject contributed equally to the generate, test, or generate plus test groups irrespective of the number of scan pairs obtained for that subject. (2) The active minus passive scan pairs from the different active conditions for a subject were weighted so that when summed across subject, each active condition contributed equally to the generate, test, or generate plus test groups irrespective of the number of scan pairs obtained for that condition.

The rationale for constraint (1) was the following. During the test phase of the replication analysis, each subject contributed a single observation that was a weighted sum of the magnitudes from the test scan pairs for that subject (see Replication Analyses: Replication in Test Group). Since each subject contributed equally to this test phase, blood flow changes from the generate phase might be more likely to replicate if they reflected each subject equally and were not biased toward subjects who contributed more scan pairs to the generate group. Constraint (2) ensured that the replication of foci in the test group reflected all conditions equally. It also ensured that the computed location of a blood flow change in the generate plus test group from an experiment was not biased toward particular conditions within the experiment.

Differential weighting of scan pairs was achieved by multiplying the normalization factors used to factor out global blood flow differences between scans. For example, by doubling the normalization factors for both scans in an active minus passive subtraction pair, the contribution of that scan pair to the total image could be halved relative to a scan pair whose normalization factors were unchanged.

\section{Averaging of Scan Pairs across Experiments}

Experiments were averaged to reveal nonsensory and nonmotor-related increases that generalized across tasks. Any image that was averaged across experiments was called a megaimage. The data from all experiments, for 
example, were combined in an Overall megaimage. Megaimages based on subsets of experiments (see "Results') were also constructed.

\section{Specific Analysis Procedures}

\section{Replication Analyses: Construction of Generate and Test Groups}

The generate group of scans provided candidate active minus passive increases for replication in the test group. Within each experiment, scan pairs were pseudorandomly assigned to the generate and test groups with the weighting constraints noted above. Some experiments contained multiple passive conditions so that each subject (or at least most subjects) could contribute independent active minus passive subtraction pairs to both the generate and test groups. This procedure carried two advantages: (1) the degrees of freedom in the test group were increased (doubled for the case in which all subjects contributed scan pairs to the generate and test group), and (2) variance between the generate and test group due to anatomical variability across subjects was minimized. For experiments involving multiple passive scans, the total number of subjects in Table 1 is therefore less than the sum of the number of subjects in the generate and test group (in the complete within case, generate $=$ test $=$ total). For Experiments 6,8 , and 9, in which each subject only received a single passive scan, subjects contributed scan pairs to either the generate or test groups but not both. For these experiments, the total number of subjects in Table 1 equals the sum of the subjects in the generate and test groups. For all experiments (1 through 9), the active and passive scans in the generate group were separate from those in the test group.

In order to increase the stability of the test data, more scan pairs were generally assigned to the test than generate group (Table 1). Megaimages that combined data across experiments were constructed by summing generate or test groups from individual experiments. In both the generate and test groups, all scan pairs were screened for head movement, and pairs with obvious movement artifact were eliminated. Behavioral performance for each subject was also reviewed. Data from an active task were eliminated if the subject performed very poorly on that task.

\section{Replication Analyses: Selection of Generate Foci}

Using a center-of-mass search algorithm (Mintun, Fox, \& Raichle, 1989), all peaks of blood flow change greater than 10 PET counts (PET counts refer to the reconstructed number of "true coincidences" detected by the PET camera from positron-electron annihilations, after images have been filtered and normalized to 1000 counts) were localized within the generate image. Since the goal of the analyses was to determine whether blood flow increases generalized over tasks and experiments, increases were only selected if they were well-sampled $(N>50)$. This criterion excluded some regions in inferior orbito-frontal cortex and superior parietal and frontal cortex. Finally, since all tasks involved visual stimuli and the present analysis was concerned with nonsensory processes, increases in occipital cortex were not analyzed.

\section{Replication Analyses: Replication in Test Group}

The generate foci were then tested for reliability. For each focus, a region of interest (ROD) was defined that included all pixels contained within a 7 -mm-radius sphere. Magnitudes were normally only calculated for scan pairs in which $90 \%$ of the pixels in the ROI had been sampled. For ROIs in inferior or superior regions that were poorly sampled, however, this restriction was relaxed to $50 \%$. The mean magnitude of blood flow change was calculated within each ROI for each scan pair in the test group. The magnitudes for the different scan pairs from a single subject were summed (since the sum of the weights for each subject was identical) so that each subject contributed a single observation to the statistical analysis (i.e., for all statistical analyses, the degrees of freedom depended on the number of subjects, not the number of scan pairs). Because of the weighting procedure (see above), all conditions within an experiment were represented equally in the test observations. A one-tailed $t$ test conducted on these observations determined which blood flow changes were significantly greater than zero in the test group. A onetailed test was appropriate since the generate group data specified the expected sign of the blood flow change in the test group.

\section{Replication Analyses: Determination of Location of Replicated Foci and Computation of $z$-Score}

For each replicated focus, the best estimate of location was determined from the generate plus test group. Using the center-of-mass search algorithm (Mintun et al., 1989), all peaks of blood flow change were localized within the generate plus test image. The focus in the generate plus test group nearest the designated focus in the generate group was then determined. The Brodmann area (BA) corresponding to this foci was determined based on the atlas of Talairach and Tournoux (1988). These assignments were necessarily approximate, since they were based on a standardized atlas, but the Brodmann system provided a convenient means of anatomical description. A $t$-score was computed for this focus and then converted to a $z$-score.

\section{Analyses of Additional Blood Flow Changes}

The absence of replicable cortical blood flow increases that generalized over tasks (see "Results") suggested the 
need for a less conservative procedure to ensure that this null finding did not result from an insensitive analysis procedure. Tables in the "Results" section therefore list all blood flow changes in the generate plus test group that exceeded a magnitude threshold of 10 PET counts. This is a liberal screen and does not constitute a statistical test. Foci from the generate plus test image that did not pass the replication procedure are of uncertain reliability.

\section{Between-Experiments Analyses}

Analyses were conducted at each focus from the overall megaimage that replicated or passed the magnitude screen, in order to assess differences in active minus passive magnitudes between experiments. For each task in an experiment, the magnitude at the selected focus was determined for each subject using a 7-mm-radius sphere. A single observation was then obtained for each subject at that focus by averaging the magnitudes over the tasks of the experiment (see above, Averaging of Scan Pairs within an Experiment). A 1 factor between-subjects ANOVA, with Experiments as the factor, was then conducted to determine if the active minus passive increases at the focus differed across experiments.

\section{Within-Experiment Analyses}

Analyses were conducted at each replicable megaimage focus that was consistent across experiments in order to assess differences in magnitudes between the conditions of each experiment. For example, blood flow changes for the read and verb-generation tasks of the Language experiment were compared. For each task in the experiment, the magnitude at the focus was determined for each subject and entered into an ANOVA or $t$ test. All analyses were within-subject, except for Visual Search 2, which involved a between-subject factor. Since the weighting procedure guaranteed that each active task in an experiment contributed equally to the image used to determine the selected foci, this analysis was not biased toward any particular task within an experiment.

\section{Correlations between Foci}

The within- and between-experiment analyses treated each experiment as a unit. The between-experiments analyses did not separate conditions within an experiment, while the within-experiment analyses did not compare conditions across experiments. This procedure was adopted because conditions within an experiment were identical across many variables that influence the magnitude of blood flow changes such as stimulus duration, eccentricity and general display characteristics, trial duration and presentation rate, and subjects (e.g., all subjects usually received all conditions within an experi- ment, while different experiments involved different subjects). Finally, tasks were often more similar within an experiment than across experiments. The four active tasks of the Spatial Attention experiment, for example, all involved a simple reaction time judgment and shifts of spatial attention to peripheral locations. Since the withinexperiment comparisons were much "cleaner" than the between-experiments comparisons, which confounded many variables, the two types were analyzed separately.

A correlational analysis was conducted, however, in which the unit of analysis was the individual conditions of each experiment. For each condition of each experiment ( $N=35$ conditions across studies), the magnitude at a focus was averaged across subjects to arrive at a single observation. These observations were then correlated across foci. The correlation between two foci reflected the degree to which changes in conditions produced concomitant variation in magnitudes for the two foci.

\section{Passive Minus Fixation Analyses}

Seven experiments (Successive Same-Different Discrimination, Visual Search 1 and 3, Spatial Attention, Memory, Language, and Cross-Modal Imagery) included a fixation point only condition, in which a more impoverished display (usually simply a fixation cross) was presented and the subjects' sole task, as in the passive condition, was to maintain fixation. Although manual responses were made in the passive condition of four of the seven experiments, no responses were made in any of the fixation conditions. Megaimages based on these experiments were constructed and analyzed via the procedures described above.

\section{Acknowledgments}

We thank Tom Videen and Tom Yang for technical assistance. This work was supported by NIH grants NS06833, NS32979, EY08775, and HL13851; the Charles A. Dana Foundation; and the McDonnell Center for the Study of Higher Brain Function.

Reprint requests should be sent to Gordon Shulman, Department of Neurology, Box 8111,660 S. Euclid, St. Louis, MO 63110, or by e-mail to gordon@petcn.wustl.edu.

\section{Notes}

1. The megaimage analysis was not applied to primary visual cortex because of the varied nature of the visual stimuli (Shulman et al., 1996a). Within nonprimary occipital cortex, the overall megaimage yielded extended regions of increase in BAs 18 and 19.

2. Six foci plotted outside the borders of the brain (as determined from a reference set of summed unsubtracted scans that are used to determine the brain boundary in the Washington University PET lab), often in regions that produced teethclenching artifacts (Drevets et al., 1992). These foci appeared in the local maximum search routine, even though the foci 
were centered outside the brain, because there was sufficient spread to produce an increase within the brain.

3 . The between-experiments analysis suggested that some of the reliable changes in the overall megaimage were caused by motor-related processes. The resulting prediction that these changes should not occur in the matched-motor megaimage was largely confirmed. The matched-motor megaimage was inspected for magnitudes greater than 10 counts within $15 \mathrm{~mm}$ of the foci from the overall megaimage. Only two foci were found, one in right frontal cortex (BA 44/45; vector distance = $3 \mathrm{~mm}$ ), and the other in left premotor cortex (BA 6; vector distance $=10 \mathrm{~mm}$ ). As noted, the right $B A 44 / 45$ focus from the overall megaimage did not replicate, while the left BA 6 focus did not yield a generate focus and showed inconsistent increases across experiments.

4. The presence of the cerebellar foci in the matched-motor megaimage is of some interest, but this megaimage included one experiment in which no overt responses were made. A controlled-motor megaimage consisting of only the four experiments in which manual responses were made in both the active and passive conditions was therefore constructed. Replicable increases were found at foci very near all three cerebellar foci from the overall megaimage (left cerebellum: $-27,-59$, $-10, z=5.96$; medial cerebellum: $-1,-75,-6, z=5.92$; right cerebellum: $27,-59,-18, z=5.01$ ).

5. The medial cerebellar increase could represent eye movement activity, which might have been different in the active and passive conditions (although EOG monitoring indicated that gross activity was similar). An eye movement hypothesis, however, does not explain either the absence of a blood flow increase in the one experiment that did not involve a motor response or the significantly greater blood flow increases in experiments involving vocal responses in the active but not passive conditions.

\section{REFERENCES}

Akshoomoff, N. A., \& Courchesne, E. (1994). ERP evidence for a shifting attention deficit in patients with damage to the cerebellum. Journal of Cognitive Neuroscience, 6 , 388-399.

Akshoomoff, N. A., Courchesne, E., Press, G., \& Iraqui, V. (1992). Contribution of the cerebellum to neuropsychology functioning: Evidence from a case of cerebellar degeneration disorder. Neuropsycbologia, 30, 315-328.

Albus, J. S. (1971). A theory of cerebellar function. Mathematical Biosciences, 10, 25-61.

Allport, A. (1989). Visual attention. In M. I. Posner (Ed.), Foundations of cognitive science (pp. 631-682). Cambridge, MA: MIT Press.

Broadbent, D. E. (1958). Perception and communication. London: Pergamon Press.

Brunia, C. H. M., \& Damen, E. J. P. (1988). Distribution of slow brain potentials related to motor preparation and stimulus anticipation in a time estimation task. Electroencepbalograpbv and Clinical Neuropbysiologv 69 , 234-243.

Buckner, R. L., Petersen, S. E., Ojemann, J. G., Miezin, F. M., Squire, L. R., \& Raichle, M. E. (1995). Functional anatomical studies of explicit and implicit memory retrieval tasks. Journal of Neuroscience, 15, 12-29.

Corbetta, M., Miezin, F. M., Dobmeyer, S., Shulman, G. L., \& Petersen, S. E. (1991). Selective and divided attention during visual discriminations of shape, color, and speed: Functional anatomy by positron emission tomography. Journal of Neuroscience, 11, 2383-2402.
Corbetta, M., Miezin, F. M., Fox, P. T., Dobmeyer, S. M., \& Petersen, S. E. (1990). Right infero-temporal cortex PET activation during object recognition tasks in humans. Society for Neuroscience Abstracts, 16, 621.

Corbetta, M., Miezin, F, M., Shulman, G. L., \& Petersen, S. E. (1991). Selective attention modulates extrastriate visual regions in humans during visual feature discrimination and recognition. In D. J. Chadwick \& W. J. Whelan (Eds.), Exploring brain functional anatomy with positron tomograpby (pp. 165-180). Chichester: Wiley (Ciba Foundation Symposium 163).

Corbetta, M., Miezin, F. M., Shulman, G. L., \& Petersen, S. E. (1993). A PET study of visuospatial attention. Journal of Neuroscience, 13, 1202-1226.

Corbetta, M., Shulman, G. L., Miezin, F. M., \& Petersen, S. E. (1995). Superior parietal cortex activation during spatial attention shifts and visual feature conjunction. Science, 270 , 802-805.

Crick, F. (1984). Function of the thalamic reticular complex: The searchlight hypothesis. Proceedings of the National Academy of Sciences of the United States of America, 81 , 4586-4590.

De Jong, $R$. (1995). The role of preparation in overlappingtask performance. Quarterly Journal of Experimental Psychology, 48A, 2-25.

Deiber, M. P., Ibanez, V., Sadato, N., \& Hallett, M. (1996). Cerebral structures participating in motor preparation in humans: A positron emission tomography study. Journal of Neurophysiology, 75, 233-247.

Deiber, M. P., Passingham, R. E., Colebatch, J. G., Friston, K. J., Nixon, P. D., \& Frackowiak, R. S. J. (1991). Cortical areas and the selection of movement: A study with positron emission tomography. Exterimental Brain Research, 84, 393-402.

Desimone, R., \& Duncan, J. (1995). Neural mechanisms of selective visual attention. Annual Review of Neuroscience, 18, 193-222.

Drevets, W. C., Videen, T. O., Price, J. L., Preskorn, S. H., Carmichael, S. T., \& Raichle, M. E. (1992). A functional anatomical study of unipolar depression. Journal of Neuroscience, 12, 3628-3641.

Fiez, J. A., Petersen, S. E., Cheney, M. K., \& Raichle, M. E. (1992). Impaired nonmotor learning and error detection associated with cerebellar damage: A single-case study. Brain, 115, 155-178.

Fox, P. T., Miezin, F. M., Allman, J. M., Van Essen, D. C., \& Raichle, M. E. (1987). Retinotopic organization of human visual cortex mapped with positron emission tomography. Journal of Neuroscience, 7, 913-922.

Fox, P. T., Mintun, M. A., Raichle, M. E., \& Herscovitch, P. (1984). A noninvasive approach to quantitative functional brain mapping with $\mathrm{H}_{2}{ }^{15} \mathrm{O}$ and positron emission tomography. Journal of Cerebral Blood Flow and Metabolism, 4, 329-333.

Fox, P. T., Perlmutter, J. S., \& Raichle, M. E. (1985). A stereotactic method of anatomical localization for positron emission tomography. Journal of Computer Assisted Tomography, 9, 141-153.

Fox, P. T., Raichle, M. E., \& Thach, W. T. (1985). Functional mapping of the human cerebellum with positron emission tomography. Proceedings of the National Academy of Sciences of the United States of America, 82, 74627466.

Gaillard, A. W. K. (1977). The late CNV wave: Preparation versus expectancy. Psycbophysiology, 14, 563-568.

Gazzaniga, M. S., \& Hillyard, S. A. (1973). Attention mechanisms following brain bisection. In S. Kornblum (Ed.), At- 
tention and performance IV (pp. 221-238). New York: Academic Press.

Graff-Radford, N. R., Damasio, H., Yamada, T., Eslinger, P. J., \& Damasio, A. R. (1985). Nonhaemorrhagic thalamic infarction: Clinical, neuropsychological and electrophysiological findings in four anatomical groups defined by computerized tomography. Brain, 108, 485-516.

Herscovitch, P., Markham, J., \& Raichle, M. E. (1983). Brain blood flow measured with intravenous $\mathrm{H}_{2}{ }^{15} \mathrm{O}$. I. Theory and error analysis. Journal of Nuclear Medicine, 24, 782789.

Ivry, R. B., \& Keele, S. W. (1989). Timing functions of the cerebellum. Journal of Cognitive Neuroscience, 1, 136-152.

Kahneman, D. (1973). Attention and effort. Englewood Cliffs, NJ: Prentice Hall.

Keele, S. W., \& Ivry, R. B. (1991). Does the cerebellum provide a common computation for diverse tasks. A timing hypothesis. Annals of the New York Academy of Sciences, $608,179-211$.

Kim, S.-G., Ugurbil, K., \& Strick, P. L. (1994). Activation of a cerebellar output nucleus during cognitive processing. $\underline{S c i-}$ ence, 265, 949-951.

Kirk, A., \& Kertesz, A. (1994). Cortical and subcortical aphasias compared. Apbasiology, 8, 65-82.

LaBerge, D., \& Buchsbaum, M. S. (1990). Positron emission tomographic measurements of pulvinar activity during an attention task. Journal of Neuroscience, 10, 613-619.

Ladavas, E. (1987). Is hemispatial deficit produced by right parietal lobe damage associated with retinal or gravitational coordinates? Brain, 110, 167-180.

Leiner, H. C., Leiner, A. L., \& Dow, R. S. (1993). Cognitive and language functions of the cerebellum. Trends in Neurosciences, $16,444-447$.

Marr, D. (1969). A theory of cerebellar cortex. Journal of Physiology, 202, 437-470.

McLeod, P. (1978). Does probe RT measure central processing demand? Quarterly Journal of Experimental Psycbology, 30, 83-89.

Middleton, F, \& Strick, P. (1994). Anatomical evidence for cerebellar and basal ganglia involvement in higher cognitive function. Science, 266, 458-461.

Mintun, M. A., Fox, P. T., \& Raichle, M. E. (1989). A highly accurate method of localizing regions of neuronal activation in the human brain with positron emission tomography. Journal of Cerebral Blood Flow and Metabolism, 9, 96103.

Olshausen, B. A., Anderson, C. H., \& Van Essen, D. C. (1993). A neurobiological model of visual attention and invariant pattern recognition based on dynamic routing of information. Journal of Neuroscience, 13, 4700-4719.

Pardo, J. V., Fox, P. T., \& Raichle, M. E. (1991). Localization of a human system for sustained attention by positron emission tomography. Nature, 349, 61-64.

Perani, D., Vallar, G., Cappa, S., Messa, C., \& Fazio, F (1987). Aphasia and neglect after subcortical stroke: A clinical/cerebral perfusion correlation study. Brain, 110, 12111229.

Petersen, S. E., Fox, P. T., Posner, M. I., Mintun, M., \& Raichle, M. E. (1989). Positron emission tomographic studies of the processing of single words. Journal of Cognitive Neuroscience, 1, 153-170.

Posner, M. I. (1978). Chronometric explorations of mind. Hillsdale, NJ: Erlbaum.

Posner, M. I., Inhoff, A., Friedrich, F. J., \& Cohen, A. (1987). Isolating attentional systems: A cognitive-anatomical analysis. Psycbobiology, 15, 107-121.

Posner, M. I., \& Petersen, S. E. (1990). The attention system of the human brain. Annual Review of Neuroscience, 13, 25-42.

Rafal, R. D., \& Posner, M. I. (1987). Deficits in human visual spatial attention following thalamic lesions. Proceedings of the National Academy of Sciences of the United States of America, 84, 7349-7353.

Raichle, M. E., Fiez, J. A., Videen, T. O., Macleod, A. K., Pardo, J. V., Fox, P. T., \& Petersen, S. E. (1994). Practice-related changes in human brain functional anatomy during nonmotor learning. Cerebral Cortex, 4, 8-26.

Rosahl, S. K., \& Knight, R. T. (1995). Role of prefrontal cortex in generation of the contingent negative variation. Cerebral Cortex, 2, 123-134.

Ruchkin, D. S., Sutton, S., Mahaffey, D., \& Glaser, J. (1986). Terminal $\mathrm{CNV}$ in the absence of motor response. Electroenceshalograbmy and Clinical Neurobbysiology 63 , 445-463.

Shulman, G. L., Corbetta, M., Buckner, R. L., Raichle, M. E., Fiez, J. A., Miezin, F. M., \& Petersen, S. E. (1997). Top-down modulation of early sensory cortex. Cerebral Cortex, 7 , 193-206.

Shulman, G. L., Fiez, J. A., Corbetta, M., Buckner, R. L., Miezin, F. M., Raichle, M. E., \& Petersen, S. E. (1997). Common blood flow changes across visual tasks: II. Decreases in cerebral cortex.Journal of Cognitive Neuroscience, 9, 648-663.

Singh, J., \& Knight, R. T. (1990). Frontal lobe contribution to voluntary movements in humans. Brain Research 531 , 45-54.

Skinner, J. E., \& Yingling, C. D. (1977). Central gating mechanisms that reulate event-related potentials and behavior. In J. E. Desmedt (Ed.), Attention, voluntary contraction and event-related cerebral potentials (pp. 30-69). Basel: Karger.

Sokoloff, L., Mangold, R., Wechsler, R., Kennedy, C., \& Kety, S. S. (1955). The effect of mental arithmetic on cerebral circulation and metabolism. Journal of Clinical Investigation, 34, 1101-1108.

Talairach, J., Szikla, G., \& Tournoux, P. (1967). Atlas d'anatomie stereotaxique du telencephale. Paris: Masson.

Talairach, J., \& Tournoux, P. (1988). Co-planar stereotaxic atlas of the buman brain. New York: Thieme Medical Publishers.

Ter-Pogossian, M. M., Ficke, D. C., Hood, J. T., Yamamoto, M., \& Mullani, N. A. (1982). PETT VI: A positron emission tomograph utilizing cesium fluoride scintillation detectors. Journal of Computer Assisted Tomograpby, 6, 125-133.

Thach, W. T. (1996). On the specific role of the cerebellum in motor learning and cognition: Clues from PET activation and lesion studies in man. Bebavioral and Brain Sciences, 3, 411-431.

Thompson, R. F. (1990). Neural mechanisms of classical conditioning in mammals. Philosobhical Transactions of the Roval Societv of London B, 329, 161-170.

Treisman, A. M., \& Davies, A. (1973). Divided attention to ear and eye. In S. Kornblum (Ed.), Attention and performance IV (pp. 101-116). New York: Academic Press.

Tsubokawa, T., \& Moriyasu, N. (1978). Motivation slow negative potential shift (CNV) related to thalamotomy. Applied Neurotbusiology 41, 202-208.

Vallar, G., \& Perani, D. (1987). The anatomy of spatial neglect in humans. In M. Jeannerod (Ed.), Neurophysiological and neuropsychological aspects of spatial neglect (pp. 235258). North-Holland: Elsevier.

Van Essen, D. C., \& DeYoe, E. A. (1995). Concurrent processing in the primate visual system. In M. S. Gazzaniga (Ed.), The cognitive neurosciences (pp. 383-400). Cambridge, MA: MIT Press. 
Walter, W. G., Cooper, R., Aldridge, V., McCallum, W. C., \& Winter, A. L. (1964). Contingent negative variation: An electrical sign of of sensorimotor association and expectancy in the human brain. Nature, 203, 380-384.
Yamamoto, M., Ficke, D. C., \& Ter-Pogossian, M. (1982). Performance study of PETT VI, a positron computed tomograph with 288 cesium fluoride detectors. IEEE Transactions on Nuclear Science, NS-29, 529-533. 


\section{This article has been cited by:}

1. Silvina G. Horovitz, Masaki Fukunaga, Jacco A. de Zwart, Peter van Gelderen, Susan C. Fulton, Thomas J. Balkin, Jeff H. Duyn. 2008. Low frequency BOLD fluctuations during resting wakefulness and light sleep: A simultaneous EEG-fMRI study. Human Brain Mapping 29:6, 671-682. [CrossRef]

2. Ye Zhang, ShiGang Feng, HongBo Feng, Feng Dong, YiYuan Tang. 2008. The task dependent interaction of the deactivation regions. Chinese Science Bulletin 53:10, 1527-1532. [CrossRef]

3. Hengyi Rao, Jiongjiong Wang, Kathy Tang, Wei Pan, John A. Detre. 2007. Imaging brain activity during natural vision using CASL perfusion fMRI. Human Brain Mapping 28:7, 593-601. [CrossRef]

4. HongBo Feng, Ye Zhang, YiYuan Tang, Jing Jin, Feng Dong, ShiGang Feng, WuTian Zhang. 2007. Deactivations during the numerical processing. Chinese Science Bulletin 52:13, 1807-1812. [CrossRef]

5. Sheila E. Blumstein , Emily B. Myers , Jesse Rissman . 2005. The Perception of Voice Onset Time: An fMRI Investigation of Phonetic Category StructureThe Perception of Voice Onset Time: An fMRI Investigation of Phonetic Category Structure. Journal of Cognitive Neuroscience 17:9, 1353-1366. [Abstract] [PDF] [PDF Plus]

6. J. Richard Jennings, Maurits W. van der Molen. 2005. Preparation for Speeded Action as a Psychophysiological Concept. Psychological Bulletin 131:3, 434-459. [CrossRef]

7. Murray Grossman, Phyllis Koenig, Chris DeVita, Guila Glosser, Peachie Moore, Jim Gee, John Detre, David Alsop. 2003. Neural Basis for Verb Processing in Alzheimer's Disease: An fMRI Study. Neuropsychology 17:4, 658-674. [CrossRef]

8. Leanne Tamm, Vinod Menon, Cindy K. Johnston, David R. Hessl, Allan L. Reiss . 2002. fMRI Study of Cognitive Interference Processing in Females with Fragile X SyndromefMRI Study of Cognitive Interference Processing in Females with Fragile X Syndrome. Journal of Cognitive Neuroscience 14:2, 160-171. [Abstract] [PDF] [PDF Plus]

9. Debra A. Gusnard, Marcus E. Raichle. 2001. Searching for a baseline: Functional imaging and the resting human brain. Nature Reviews Neuroscience 2:10, 685-694. [CrossRef]

10. Tetsuya Iidaka , Nicole D. Anderson, Shitij Kapur, Roberto Cabez , Fergus I. M. Craik . 2000. The Effect of Divided Attention on Encoding and Retrieval in Episodic Memory Revealed by Positron Emission TomographyThe Effect of Divided Attention on Encoding and Retrieval in Episodic Memory Revealed by Positron Emission Tomography. Journal of Cognitive Neuroscience 12:2, 267-280. [Abstract] [PDF] [PDF Plus]

11. K. Sathian, Tony J. Simon, Scott Peterson, Gargi A. Patel, John M. Hoffman, Scott T. Grafton. 1999. Neural Evidence Linking Visual Object Enumeration and AttentionNeural Evidence Linking Visual Object Enumeration and Attention. Journal of Cognitive Neuroscience 11:1, 36-51. [Abstract] [PDF] [PDF Plus] 